\title{
La distribución del ingreso en Argentina, 1974-2000
}

\section{Oscar Altimir}

CEPAL, Naciones Unidas

Oaltimir@eclac.cl

\section{Luis Beccaria}

Universidad Nacional

de General Sarmiento,

Buenos Aires, Argentina

lbeccari@ungs.edu.ar

\section{Martín González Rozada}

Universidad Torcuato Di Tella,

Buenos Aires, Argentina

mrozada@utdt.edu
En el último cuarto de siglo, en Argentina la distribución del ingreso empeoró persistentemente. El artículo utiliza el análisis de microsimulación para descomponer el impacto que ejercieron los cambios laborales sobre la distribución del ingreso familiar. El deterioro se produjo, en los años setenta, por la reducción real de las remuneraciones y su dispersión relativa; en los ochenta, a través del creciente desempleo por sucesivas crisis; en los noventa, bajo el nuevo orden económico, como resultado del desempleo generado por la reestructuración productiva y el aumento de la participación, y en la última fase, por una mayor desigualdad en las remuneraciones. Se concluye que el nuevo estilo de funcionamiento de la economía determina, más allá de la apreciación cambiaria y del ulterior colapso del régimen macroeconómico, una menor elasticidad del empleo con respecto al crecimiento — con el consiguiente desempleo estructural — y mayores diferencias de salario por niveles de calificación. 


\section{La evolución de la distribución del ingreso}

El análisis dinámico de la distribución del ingreso está altamente condicionado por la disponibilidad de microdatos de encuestas comparables. En el caso de Argentina, ese análisis se ve limitado por la disponibilidad de datos de la Encuesta Permanente de Hogares (EPH): el año 1974 y desde los años ochenta en adelante hay datos para el Gran Buenos Aires, a lo que se agrega a partir de 1990 la disponibilidad de datos comparables para diez aglomeraciones urbanas del interior del país. ${ }^{1}$

Sin embargo, es posible echar una mirada retrospectiva más larga, circunscrita a la probable evolución de la desigualdad, basada en mediciones de diferente origen $-\mathrm{y}$, por consiguiente, no estrictamente comparables - anteriores a 1974. Esto se ha hecho en otros trabajos (Altimir, 1986; Altimir y Beccaria, 2000a; Altimir y Beccaria, 2001) y ha servido para determinar que: i) entre 1953 y 1961, con un crecimiento por habitante superior a $2 \%$ anual, la desigualdad de los hogares a nivel nacional habría aumentado sólo en un 5\% del coeficiente de Gini, aunque la de los hogares no agrícolas se habría incrementado en un $10 \%$; y ii) la desigualdad en el Gran Buenos Aires (y, presumiblemente, la del total urbano) se habría mantenido en torno a una tendencia estacionaria a lo largo de los años sesenta y los primeros años setenta, hasta $1974 .^{2}$

Nuestro análisis de la evolución de la distribución del ingreso se extiende desde 1974 hasta el año 2000, sobre la base de los datos de la EPH. ${ }^{3}$ Se basa en la

Agradecemos los comentarios de José Antonio Ocampo y Juan V. Sourrouille, sin responsabilidades por el resultado final.

${ }^{1}$ El conjunto de veintiocho aglomeraciones urbanas que ha alcanzado a cubrir el Instituto Nacional de Estadística y Censos (INDEC) con la EPH se ha ido constituyendo a lo largo del tiempo y además ha sufrido la discontinuidad de ciertas aglomeraciones en algunos años.

${ }^{2}$ Sin embargo, si los datos de las encuestas se ajustan por el efecto de la subdeclaración de ingresos, la concentración podría haber tendido a aumentar moderadamente entre 1970 y 1974/1975 (Altimir, 1986). Como los datos originales de las encuestas muestran una concentración prácticamente constante entre 1970 y 1975, habría que concluir que pese al notable aumento de los salarios reales en este último año (que se observa más adelante en el gráfico 4), la situación distributiva imperante en ese mismo año (en que se registró una notable expansión de la actividad económica) no difería mucho de la de los años precedentes.

${ }^{3}$ Esto no implica desconocer la posible subestimación y omisiones de ingresos de que pueda adolecer la EPH ni el efecto que ellas pue- comparación de las situaciones distributivas que imperaron en años culminantes de cada período dominado por un régimen de funcionamiento macroeconómico y una política determinados, en que el nivel de actividad económica se hallara en un máximo relativo y, por lo tanto, la economía se encontrara más cercana a su frontera de producción ${ }^{4}$ (cuadro 1). Esta forma de seleccionar los períodos responde, dentro de la disponibilidad de datos, a la precaución elemental de disminuir la importancia de disturbios coyunturales en la determinación de los resultados distributivos, de manera de discernir lo más posible las tendencias y cambios estructurales que han moldeado la distribución del ingreso en este cuarto de siglo.

Si se consideran sólo los años seleccionados de acuerdo con el criterio señalado, se observa una tendencia al constante empeoramiento de la distribución del ingreso de los hogares (y por consiguiente del bienestar), a lo largo del cuarto de siglo y a un ritmo casi uniforme que termina por elevar la desigualdad desde un coeficiente de Gini de 0.36 en 1974 a otro de 0.51 en 2000 (gráfico 1). Asimismo, se observan empeoramientos temporarios por sobre esa tendencia durante las crisis: la hiperinflación de fines de los ochenta, el episodio del tequila y la más reciente recesión, que aún perdura. Por otra parte, en el período 1991/1993 se aprecia que la desigualdad se mantiene por debajo de la tendencia indicada.

Sin embargo, la distribución del ingreso entre los perceptores individuales ocupados (que refleja más las remuneraciones generadas en el aparato productivo) evolucionó de manera algo diferente: después de un empeoramiento - más agudo que el de la distribución entre los hogares - en 1974/1980, la tendencia

\footnotetext{
dan tener sobre la concentración del ingreso; al respecto, véase Altimir (1986) y Altimir y Beccaria (2000a). Equivale, sin embargo, a suponer que la estructura de la subestimación y las omisiones no ha cambiado significativamente en el sentido de aumentar o disminuir la diferencia relativa entre la desigualdad medida y la desigualdad efectiva.

${ }^{4}$ No es el caso, sin embargo, de 1990, elegido por ser el último año previo al cambio de régimen, ni del año 2000, último para el que se disponía de datos pero en el que estaba vigente la recesión iniciada a mediados de 1998 .
} 
CUADRO 1

Argentina: Marco macroeconómico de las observaciones distributivas

\begin{tabular}{|c|c|c|c|c|c|c|c|c|c|c|}
\hline \multirow{2}{*}{\multicolumn{2}{|c|}{$\begin{array}{l}\text { Períodos } \\
\text { macroeconómicos }\end{array}$}} & \multirow[t]{2}{*}{$\begin{array}{l}\text { Observaciones } \\
\text { distributivas }\end{array}$} & \multirow{2}{*}{$\begin{array}{l}\text { Ingreso medio } \\
\text { real per cápita } \\
\text { de los hogares, } \\
\text { Gran Buenos Aires }\end{array}$} & \multicolumn{2}{|c|}{$\begin{array}{c}\text { NIVEL PIB } \\
(1980=100)\end{array}$} & \multirow{2}{*}{$\begin{array}{l}\text { Empleo } \\
\text { urbano } \\
(1980=100)\end{array}$} & \multirow{2}{*}{$\begin{array}{c}\text { Desempleo } \\
\text { urbano } \\
(\%)\end{array}$} & \multirow{2}{*}{$\begin{array}{l}\text { Inflación } \\
\text { mensual } \\
(\%)\end{array}$} & \multirow{2}{*}{$\begin{array}{l}\begin{array}{c}\text { Salario } \\
\text { real }\end{array} \\
(198\end{array}$} & \multirow{2}{*}{$\begin{array}{c}\text { Tipo de } \\
\text { cambio real } \\
0=100)\end{array}$} \\
\hline & & & & Total & No agrícola & & & & & \\
\hline 1973-1975: & $\begin{array}{l}\text { La estabilización } \\
\text { populista }\end{array}$ & III 1974 & 110.1 & 90.0 & 89.2 & 92.8 & 3.4 & 3.0 & 118.5 & 125.3 \\
\hline 1976-1980: & $\begin{array}{l}\text { Estabilización } \\
\text { ortodoxa con } \\
\text { liberalización }\end{array}$ & III 1980 & 100.0 & 101.8 & 101.4 & 100.0 & 2.5 & 4.2 & 100.0 & 100.0 \\
\hline 1981-1984: & $\begin{array}{l}\text { Ajuste caótico y } \\
\text { regreso al populismo }\end{array}$ & & & & & & & & & \\
\hline 1985-1986: & $\begin{array}{l}\text { La estabilización } \\
\text { transitoria }\end{array}$ & III 1986 & 91.7 & 99.7 & 98.7 & 108.5 & 5.2 & 7.6 & 92.6 & 268.2 \\
\hline 1987-1990: & $\begin{array}{l}\text { Deslizamiento } \\
\text { hacia la } \\
\text { hiperinflación }\end{array}$ & III 1990 & 62.8 & 91.2 & 97.4 & 114.8 & 6.2 & 13.9 & 62.9 & 168.7 \\
\hline \multirow[t]{4}{*}{ 1991-2000: } & La estabilización & III 1991 & 72.7 & 100.5 & 99.4 & 118.8 & 6.0 & 1.9 & 70.0 & 124.5 \\
\hline & y el nuevo & III 1994 & 82.4 & 126.9 & 126.8 & 120.4 & 12.2 & 0.6 & 81.0 & 101.9 \\
\hline & régimen de la & III 1997 & 81.0 & 141.5 & 142.1 & 129.1 & 13.7 & 0.3 & 75.4 & 105.1 \\
\hline & economía & III 2000 & 81.2 & 139.9 & 140.2 & & 14.7 & 0.1 & 78.4 & 113.3 \\
\hline
\end{tabular}

Fuente: Elaboración propia, basada en datos de la CEPAL y de la EPH.

GRAFICO 1

Argentina: Distribución del ingreso de los hogares y los perceptores individuales, 1974-2000

(Coeficientes de Gini)

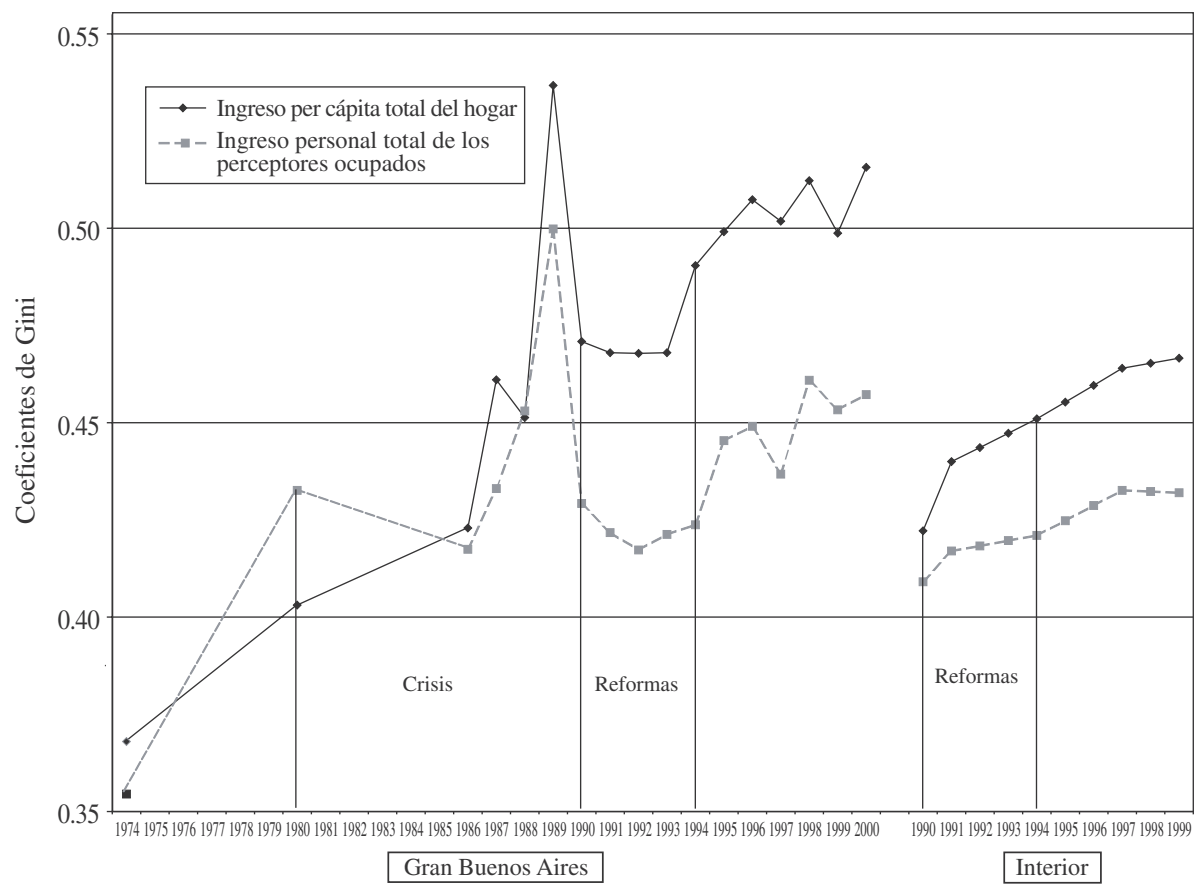

Fuente: Elaboración propia, basada en datos de la EPH. 
(marcada en nuestra interpretación por las situaciones distributivas más cercanas a lo estructural) se mantuvo estacionaria hasta $1994,{ }^{5}$ para luego ascender un 3\% del coeficiente de Gini hacia 1997. Posteriormente, con la economía ya en recesión, la desigualdad osciló en torno a una tendencia creciente, ubicándose en 2000 un $4.7 \%$ por encima de la de 1997 , último año "normal" desde la perspectiva de la actividad económica (gráfico 1).

El contraste entre la evolución de la distribución del ingreso de los hogares y la de los perceptores ocupados ha estado determinado, como se analiza más adelante, por los cambios en la participación y el desempleo. La influencia de estos dos factores y de la estructura de las remuneraciones sobre la distribución del ingreso de los hogares se analiza mediante un ejercicio de microsimulación.

La evolución de la desigualdad de ingresos en las ciudades del interior en los años noventa no difiere mucho de la observada en el Gran Buenos Aires, especialmente en los años que marcan la tendencia, ${ }^{6}$ en los cuales el grado de concentración de los ingresos personales en las diez ciudades del interior analizadas ${ }^{7}$ fue muy cercano al del área metropolitana. ${ }^{8} \mathrm{La}$ desigualdad de los ingresos familiares en el interior también se comportó de manera similar - a niveles menores del coeficiente de Gini- a la observada en la distribución de los hogares metropolitanos, sólo que allí el agravamiento mayor ocurrió ya en 1991, en lugar de 1994 (gráfico 1).

\section{II}

\section{Los ingresos reales}

\section{El deterioro, por deciles de ingreso}

La evolución indicada de la distribución relativa del ingreso nominal de los hogares implica una evolución también inequitativa en términos reales. El ingreso medio real per cápita de los hogares en el Gran Buenos Aires se fue reduciendo tendencialmente desde 1974 hasta 1990/1991, para luego fluctuar en torno a un nivel $20 \%$ inferior al de $1980^{9}$ (cuadro 1). Esta

\footnotetext{
${ }^{5}$ La disminución, entre 1980 y 1986, de $3.8 \%$ en el valor del coeficiente de Gini de esta distribución es estadísticamente significativa al $95 \%$, sobre la base de los intervalos de confianza estimados por un procedimiento de bootstrapping que permitió generar nuestras alternativas. En cambio, las diferencias entre los valores del coeficiente de Gini para 1986, 1990 y 1994 no superan el 3\% y no son estadísticamente significativas.

${ }^{6}$ En torno a ésta, los valores anuales del coeficiente de Gini de la distribución agregada para las diez ciudades casi no registran oscilaciones (gráfico 1).

${ }^{7} \mathrm{Se}$ trata de las siguientes aglomeraciones urbanas, para las que se dispuso de los microdatos de la EPH sobre los años noventa: Córdoba, Jujuy, La Plata, Mendoza, Neuquén, Rosario, Salta, Santa Rosa, Río Gallegos y Tucumán.

${ }^{8}$ Los valores del coeficiente de Gini para ambos dominios registraron diferencias estadísticamente no significativas (en torno a 1\%) para 1991, 1994 y 1997. No así en 1990, cuando la distribución del interior del país registró un coeficiente de Gini 5\% inferior al del Gran Buenos Aires; si se toma este año como referencia, la desigualdad de los ingresos personales habría aumentado algo más que en el área metropolitana.

${ }^{9} \mathrm{El}$ ingreso medio en el conjunto urbano (Gran Buenos Aires más diez ciudades del interior) ha sufrido un deterioro igual o mayor:
}

evolución incluye la pérdida de poder adquisitivo debida al aumento de los precios relativos aplicables a los ingresos de los hogares que se derivó de la apreciación cambiaria registrada a partir de $1990 .{ }^{10}$

Si se toma 1980 como base de comparación (como se hace en el gráfico 2) ${ }^{11}$ las pérdidas relativas de ingresos reales entre 1974 y ese año decrecieron con el nivel de ingreso, salvo en el decil más bajo — cuya pérdida fue similar a la caída promedio- y el decil superior, que no perdió prácticamente nada. En cambio, la pérdida en términos reales entre 1980 y 1986 — de $8 \%$ en promedio - fue más equitativa, aunque siempre menor en el quintil superior de ingresos. La

tanto en 1991 como en 1994, se ubicó 8\% por debajo del ingreso medio del componente metropolitano; en 1999/2000, era 10\% inferior a éste, con el consiguiente rezago del componente urbano del interior.

${ }^{10} \mathrm{El}$ aumento de precios de los bienes no transables se manifestó en incrementos del índice de precios al consumidor (IPC) superiores en alrededor de $35 \%$ a la evolución de los precios implícitos en el producto. Esta es la razón principal por la que el ingreso medio real de los hogares aumentó, en los noventa, mucho menos que el ingreso nacional per cápita (cuadro 1).

111974 no constituye una base apropiada de comparación para todo el período, dado que en ese año se alcanzó el máximo absoluto de salario real del período 1960/2000 (véase más adelante el gráfico 4), en una situación macroeconómica que resultó insostenible. En cambio, el nivel de salario real de 1980 ya había sido alcanzado a mediados de los sesenta y a principios de los setenta y volvió a registrarse a mediados de los ochenta. 


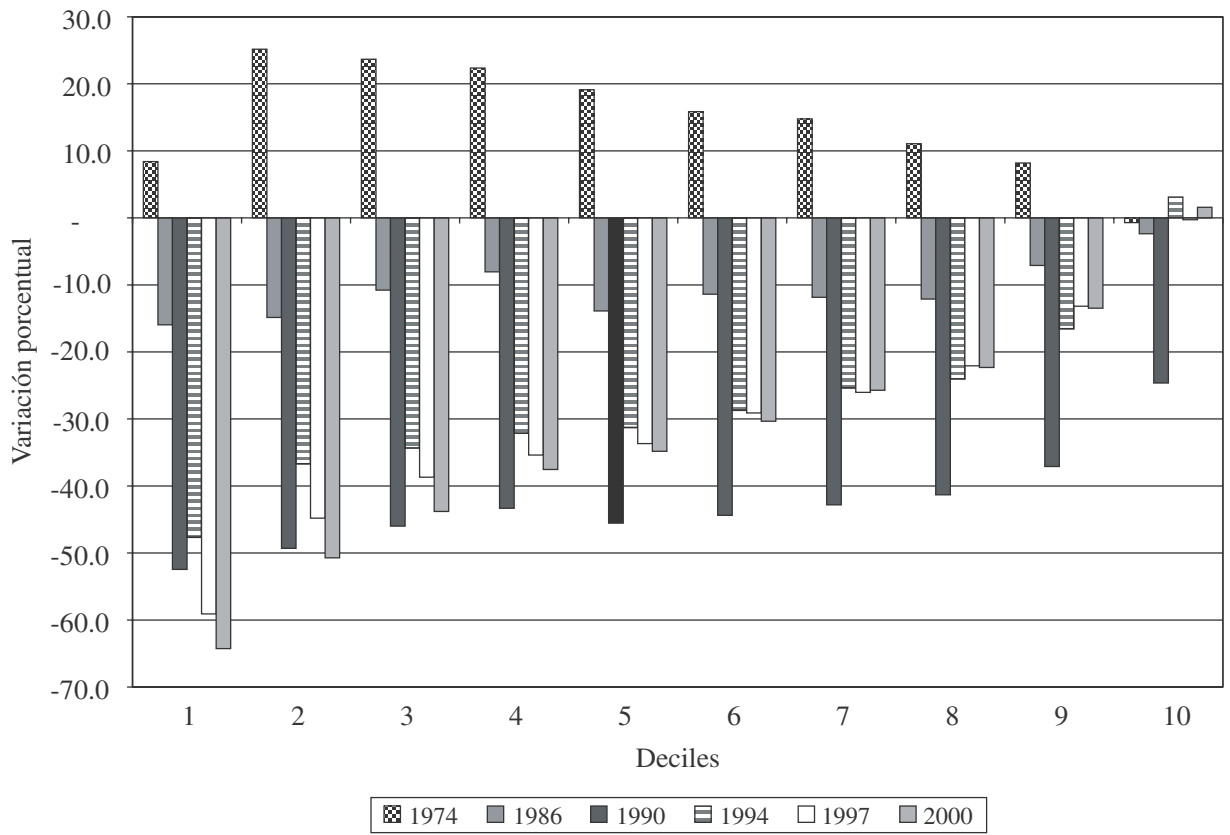

Fuente: Elaboración propia, basada en datos de la EPH.

gran caída de ingresos asociada con la crisis y la hiperinflación de fines de los ochenta y principios de los noventa fue muy generalizada y resultó casi neutral entre los estratos de ingresos medios y bajos (sobre todo, comparando los niveles alcanzados por éstos con los de 1986); sin embargo, la pérdida del decil superior fue menor que el promedio. La recuperación parcial de los ingresos entre 1990 y 1994 fue inequitativa: creció con el nivel de ingreso, al punto que el decil superior llegó a registrar un ingreso real superior al que tenía en 1980. La evolución posterior de los ingresos reales fue claramente regresiva: se deterioraron —de forma inversamente proporcional a sus respectivos niveles- los ingresos del 60\% inferior de los hogares y mejoraron los ingresos reales de los tres deciles superiores. Con ello, la situación distributiva a fines del siglo XX representa, en términos reales, una notable regresión con respecto a 1980 (gráfico 2).

\section{La pobreza}

La incidencia de pobreza en el Gran Buenos Aires ${ }^{12}$ fue en aumento a lo largo de todo el período, más allá del salto que registrara con la hiperinflación de 1989/
1990. En 1974 era inferior al 5\% de los hogares, en 1980 fue cercana a 6\%, en 1986 superaba el 9\%, en 1990 llegó a abarcar el 25\% de los hogares, para descender luego por debajo de 15\% en 1994 y volver a trepar hasta $21 \%$ en el año 2000.

Como para identificar a los pobres se particiona la distribución del ingreso mediante una línea de pobreza que se mantiene en términos reales, la incidencia de pobreza varía con el ingreso real del conjunto de los hogares y su distribución por niveles de ingreso. En el cuadro 2 se descompone la variación de la incidencia de pobreza en los diferentes subperíodos. ${ }^{13}$

\footnotetext{
${ }^{12}$ Hasta hace muy poco, sólo se disponía de una línea oficial de pobreza para el Gran Buenos Aires. Por otro lado, la estimaciones oficiales de la incidencia de pobreza en el Gran Buenos Aires comienzan en 1986, por lo que las indicadas para 1974 y 1980 provienen de Altimir y Beccaria (1998), y fueron obtenidas replicando los procedimientos utilizados en las estimaciones oficiales.

${ }^{13} \mathrm{P}(0)$ de los indicadores de pobreza de Foster, Greer y Thorbecke, que mide la proporción de hogares pobres en el total de hogares. Las magnitudes del cambio de la incidencia de pobreza siguen la tendencia de las estimaciones oficiales pero no coinciden con ellas, puesto que se basan en datos de ingresos de la EPH ajustados por subestimación (Altimir y Beccaria, 1998).
} 
CUADRO 2

Gran Buenos Aires: Descomposición del cambio de la incidencia de pobreza absoluta

(Puntos porcentuales)

\begin{tabular}{|c|c|c|c|c|}
\hline Período & Cambio total & Efecto ingreso medio & Efecto distribución & Interacción \\
\hline 1974-1980 & $\ldots$ & 1.5 & -1.4 & 0.1 \\
\hline 1980-1986 & 3.2 & 2.1 & 0.8 & 0.3 \\
\hline 1986-1991 & 2.7 & 1.4 & 1.8 & -0.5 \\
\hline 1991-1994 & 0.4 & -2.3 & 2.7 & 0.4 \\
\hline 1994-1997 & 4.1 & 2.6 & 1.9 & -0.4 \\
\hline $1997-2000$ & 1.4 & -0.6 & 2.1 & -0.1 \\
\hline
\end{tabular}

Fuente: Elaboración propia, basada en datos de la EPH.

Durante la década de crisis, la significativa expansión de la pobreza absoluta obedeció, en sus dos terceras partes, a la caída de los ingresos reales de los hogares asociada a la recesión y al empeoramiento de los términos del intercambio. ${ }^{14}$ Empero, un tercio del aumento de la incidencia obedeció a los cambios distributivos. La recuperación y expansión de la economía entre 1991 y 1994 tuvo un efecto que favoreció la disminución de la pobreza, pero que fue totalmente compensado por el efecto desfavorable de los cambios distributivos. Entre 1994 y 1997, el debilitamiento del ingreso real y el empeoramiento distributivo se combinaron, dando por resultado un nuevo aumento de la incidencia de pobreza absoluta. En cambio, en los años subsiguientes hasta llegar al 2000, fue el continuado deterioro distributivo el único responsable de la elevación de la pobreza (cuadro 2).

\section{III}

\section{Las tendencias del mercado de trabajo}

La fuerza de trabajo creció lentamente en los años setenta y ochenta, pero pasó a expandirse rápidamente en los noventa. La tasa de actividad urbana tendió a reducirse a todo lo largo del decenio de $1970,{ }^{15}$ llegando a $38.5 \%$ en 1980. En la primera mitad de los años ochenta la participación se estancó para luego elevarse sostenidamente en la segunda mitad de esa década, frente a la reducción e inestabilidad de los ingresos. Posteriormente, la tasa agregada de actividad en las áreas urbanas pasó de $39.5 \%$ en 1991 a más de $42 \%$ de la población total a partir de 1997 (gráfico 3). ${ }^{16}$

\footnotetext{
${ }^{14}$ Hacia el final de la década, por el efecto de la devaluación de la moneda sobre los precios de los bienes transables en el IPC.

${ }^{15}$ En la primera mitad de la década, por el efecto ingreso, frente al aumento de las remuneraciones. En la segunda mitad, en cambio, por el efecto sustitución - frente a la reducción de las remuneraciones- y el desaliento ante la menor creación de empleo formal (Altimir y Beccaria, 2000b).

${ }^{16}$ Este considerable aumento en el conjunto urbano se debe casi exclusivamente al registrado en el Gran Buenos Aires, donde la
}

La creación de puestos de trabajo — formales e informales - no alcanzó en el decenio de 1980 ni aun el moderado ritmo de expansión de la oferta y desembocó, en los años noventa, en una notoria insuficiencia de absorción, incluso en épocas de rápido incremento de la actividad económica. En consecuencia, el desempleo urbano trepó tres escalones durante el decenio de 1980: en torno al 5\% en los primeros años, alrededor del $6 \%$ en $1985 / 1988$ y por encima de $7 \%$ a partir de la crisis hiperinflacionaria. Junto con llegar las reformas y la estabilidad, se abrieron ampliamente los portones del desempleo: en tres años (entre 1992 y 1995/1996, en pleno ajuste tras el efecto tequila), la desocupación se elevó del $7 \%$ a más del $17 \%$ de la fuerza de trabajo urbana, para luego normalizarse en torno al 14\% (entre 1997 y 1999) y volver a empinar-

tasa de participación pasó de $40.9 \%$ a más de $45 \%$, en gran parte debido al aumento de la tasa de participación femenina (Altimir y Beccaria, 2000b). 
se, con la recesión, por encima del 17\% en 2001 (gráfico 3 ).

La ampliación del desempleo en los noventa fue un fenómeno generalizado, que abarcó la totalidad del país y personas de diferentes características. Los jóvenes continuaron exhibiendo las mayores tasas, pero el aumento de la desocupación afectó similarmente a todos los grupos etarios. Sin embargo, su incidencia aumentó algo más entre las mujeres que entre los varones, en paralelo con la elevación de la participación femenina en la fuerza de trabajo. Por otro lado, se expandió de manera preocupante la incidencia del desempleo entre los jefes de hogar, que subió desde $2 \%$ $3 \%$ hasta alrededor de $10 \%$ en la última coyuntura expansiva (1997), y se agravó en la posterior recesión (Altimir y Beccaria, 2000b). El aumento de la desocupación fue bastante generalizado también por niveles de ingreso, aunque fue algo más intenso en algunos estratos medios y -al combinarse con menores tasas de actividad - afectó más gravemente el bienestar de los estratos de menores ingresos, como se verá más adelante (cuadro 3).

La tasa de empleo total ha fluctuado entre $35 \%$ y $37 \%$ de la población desde 1980, con oscilaciones asociadas en general al ciclo económico, que se ampliaron en los años noventa ${ }^{17}$ (gráfico 3). Sin embargo, la ocupación total incluye tanto el empleo informal en actividades de baja productividad como el subempleo horario involuntario. Damill, Frenkel y Maurizio (2002) han analizado la evolución del empleo de tiempo completo (incluido el subempleo voluntario) y encuentran una tendencia marcadamente declinante, que se acentúa a partir de los comienzos de la década de 1990: desde un nivel de entre $35 \%$ y $36 \%$ en los primeros años ochenta, a 32\% en 1994 y también en 2000. Esto significa que el subempleo involuntario se ha ampliado, tendencialmente, de alrededor de $2 \%$ a $6 \%$ de la población urbana.

Por otro lado, la reducción de los empleos de tiempo completo afectó en especial a los varones y a los jefes de hogar. Además, se concentró en el sector manufacturero, donde también se redujeron las tasas de empleo de mujeres y trabajadores secundarios quienes, sin embargo, aumentaron su participación en el empleo correspondiente a servicios (Damill, Frenkel y Maurizio, 2002).

${ }^{17}$ Durante la recesión de 1995/1996 llegó a caer por debajo del $35 \%$.
Entre 1974 y 1980 prácticamente se estancó la productividad agregada del trabajo en las actividades no agrícolas. ${ }^{18}$ Diez años después, al comenzar la década de 1990, el producto no agrícola era menor y el empleo urbano se había expandido un $10 \%$, con la consiguiente reducción de la productividad del trabajo (cuadro 1). Esta caída estuvo parcialmente asociada al aumento de la actividad económica informal, que pasó del $38 \%$ al $42 \%$, pero no se descarta el deterioro de la productividad en empresas formales: una encuesta en establecimientos medianos y grandes del sector industrial reveló el estancamiento de la productividad entre 1980 y 1990 (Altimir y Beccaria, 2000b).

Entre 1991 y 1994, el producto no agrícola se expandió 28\%; sin embargo, el empleo urbano casi no varió (cuadro 1). Esto representó un rápido aumento de la productividad media del trabajo que reflejó, en parte, la ocupación de capacidad ociosa asociada a la reactivación de la economía y, en parte, un incremento del producto por persona en la frontera de producción, vinculado a la reestructuración productiva. ${ }^{19} \mathrm{En}$ cambio, entre 1994 y 1997 el incremento de $11.5 \%$ en el nivel de actividad económica fue acompañado por una expansión del empleo urbano de $7.2 \%$ y, durante la recesión posterior de 1998/2000, éste se amplió otro 5\%.

Damill, Frenkel y Maurizio (2002) encuentran que la ocupación de tiempo completo en el Gran Buenos Aires muestra un cambio significativo en los años noventa, reflejado en una contracción de la tasa de empleo e interpretado como el impacto del nuevo escenario macroeconómico y de incentivos sobre la demanda de trabajo de tiempo completo. Encuentran, asimismo, que el período de ajuste al nuevo entorno podría considerarse completado hacia fines de $1996 .{ }^{20}$

\footnotetext{
${ }^{18}$ Luego de haberse expandido a más del 3\% anual entre 1960 y 1970, cuando el producto creció a una tasa cercana a 5\% y el empleo urbano lo hizo al $1.4 \%$ anual.

${ }^{19}$ Frenkel y González Rozada (1998) estiman que la mitad del aumento medio de la productividad en la industria se explica por el efecto ciclo (aumento de eficiencia en el uso de los recursos existentes por aumento de la actividad económica) y la otra mitad por el aumento de la relación capital/producto y la incorporación de tecnología, incorporada y desincorporada.

${ }^{20}$ Formulan un modelo de la demanda de trabajo concibiendo el ajuste de ésta a un nuevo entorno como un proceso gradual, y utilizan dos variables ficticias: una para la década de 1990 y otra para las observaciones posteriores a 1996. El coeficiente de la primera variable ficticia (para toda la década) implica una contracción adicional de la tasa de empleo de tiempo completo; el de la segunda variable ficticia (para las observaciones posteriores a 1996) es positivo y compensa aproximadamente el efecto contractivo del coeficiente que corresponde a la primera (Damill, Frenkel y Maurizio, 2002, p. 47).
} 
GRAFICO 3

Argentina: Tasas de empleo, desempleo y actividad

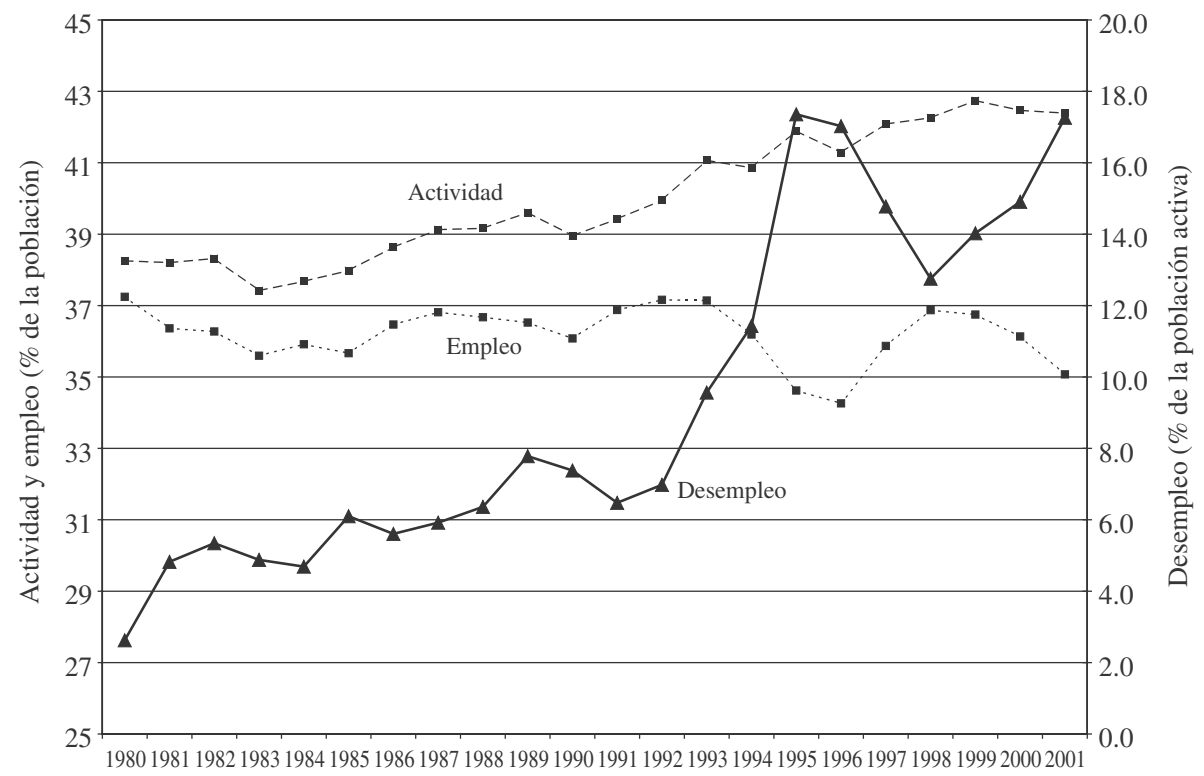

Años

Fuente: Elaboración propia, basada en datos de la EPH.

CUADRO 3

Tasa de actividad y desempleo por estrato de ingreso familiar per cápita

\begin{tabular}{|c|c|c|c|c|c|c|c|c|c|c|c|c|c|c|c|c|}
\hline \multirow{2}{*}{$\begin{array}{l}\text { Decil del } \\
\text { ingreso familiar } \\
\text { per cápita }^{a}\end{array}$} & \multicolumn{2}{|c|}{1974} & \multicolumn{2}{|c|}{1980} & \multicolumn{2}{|c|}{1986} & \multicolumn{2}{|c|}{1989} & \multicolumn{2}{|c|}{1990} & \multicolumn{2}{|c|}{1994} & \multicolumn{2}{|c|}{1997} & \multicolumn{2}{|c|}{2000} \\
\hline & $\begin{array}{l}\text { Tasa de } \\
\text { actividad }\end{array}$ & $\begin{array}{l}\text { Tasa de } \\
\text { desocu- } \\
\text { pación }\end{array}$ & $\begin{array}{c}\text { Tasa de } \\
\text { actividad }\end{array}$ & $\begin{array}{l}\text { Tasa de } \\
\text { desocu- } \\
\text { pación }\end{array}$ & $\begin{array}{c}\text { Tasa de } \\
\text { actividad }\end{array}$ & $\begin{array}{l}\text { Tasa de } \\
\text { desocu- } \\
\text { pación }\end{array}$ & $\begin{array}{l}\text { Tasa de } \\
\text { actividad }\end{array}$ & $\begin{array}{l}\text { Tasa de } \\
\text { desocu- } \\
\text { pación }\end{array}$ & $\begin{array}{l}\text { Tasa de } \\
\text { actividad }\end{array}$ & $\begin{array}{l}\text { Tasa de } \\
\text { desocu- } \\
\text { pación }\end{array}$ & $\begin{array}{l}\text { Tasa de } \\
\text { actividad }\end{array}$ & $\begin{array}{l}\text { Tasa de } \\
\text { desocu- } \\
\text { pación }\end{array}$ & $\begin{array}{l}\text { Tasa de } \\
\text { actividad }\end{array}$ & $\begin{array}{l}\text { Tasa de } \\
\text { desocu- } \\
\text { pación }\end{array}$ & $\begin{array}{l}\text { Tasa de } \\
\text { actividad }\end{array}$ & $\begin{array}{l}\text { Tasa de } \\
\text { desocu- } \\
\text { pación }\end{array}$ \\
\hline \multicolumn{17}{|c|}{ Gran Buenos Aires } \\
\hline 1 & 21.1 & 10.4 & 20.9 & 5.1 & 21.9 & 20.6 & 23.6 & 30.2 & 22.4 & 30.0 & 27.8 & 47.2 & 32.4 & 40.6 & 30.4 & 44.9 \\
\hline 2 & 25.0 & 4.6 & 23.6 & 1.2 & 23.1 & 10.3 & 27.5 & 16.3 & 24.8 & 9.5 & 29.2 & 21.3 & 33.2 & 25.6 & 31.9 & 22.4 \\
\hline 3 & 27.3 & 3.9 & 29.2 & 4.3 & 30.7 & 8.2 & 25.7 & 11.0 & 24.9 & 9.4 & 30.2 & 21.4 & 33.4 & 21.5 & 36.4 & 23.8 \\
\hline 4 & 31.9 & 2.0 & 32.6 & 2.5 & 33.7 & 5.3 & 36.4 & 10.9 & 32.2 & 10.5 & 37.1 & 16.8 & 38.4 & 18.1 & 35.9 & 20.3 \\
\hline 5 & 34.0 & 3.6 & 32.8 & 1.0 & 29.0 & 3.9 & 33.8 & 7.1 & 35.7 & 7.8 & 40.7 & 16.2 & 41.7 & 16.6 & 38.7 & 16.5 \\
\hline 6 & 36.5 & 3.2 & 38.9 & 3.2 & 38.5 & 3.3 & 35.3 & 8.5 & 33.4 & 4.8 & 41.5 & 13.4 & 42.9 & 14.9 & 45.7 & 11.9 \\
\hline 7 & 45.3 & 2.1 & 45.3 & 1.8 & 46.6 & 3.4 & 42.8 & 4.0 & 41.5 & 4.8 & 48.6 & 10.0 & 47.4 & 11.5 & 50.1 & 13.3 \\
\hline 8 & 50.9 & 1.3 & 49.9 & 1.2 & 47.0 & 1.6 & 48.2 & 2.9 & 47.3 & 3.2 & 51.9 & 7.1 & 54.4 & 9.3 & 51.4 & 8.3 \\
\hline 9 & 53.7 & 1.5 & 48.4 & 1.6 & 52.8 & 1.9 & 51.4 & 1.5 & 54.9 & 1.5 & 53.7 & 5.1 & 60.1 & 5.9 & 58.1 & 7.4 \\
\hline 10 & 61.6 & 0.8 & 52.9 & 0.8 & 57.0 & 0.8 & 58.2 & 1.8 & 64.2 & 2.3 & 65.4 & 2.2 & 62.6 & 4.1 & 63.9 & 3.3 \\
\hline Total & 38.7 & 2.7 & 37.5 & 2.0 & 38.0 & 4.6 & 38.3 & 7.5 & 38.2 & 6.6 & 42.6 & 13.4 & 44.6 & 14.7 & 44.2 & 14.9 \\
\hline \multicolumn{17}{|c|}{ Diez aglomeraciones del interior } \\
\hline 1 & -- & tor & & & & & & & & & 24.4 & 33.7 & 27.5 & 38.2 & 28.5 & 44.6 \\
\hline 2 & & & & & & & & & & & 30.0 & 19.9 & 29.1 & 26.2 & 30.9 & 27.1 \\
\hline 3 & & & & & & & & & & & 31.7 & 15.1 & 31.5 & 17.5 & 33.2 & 20.6 \\
\hline 4 & & & & & & & & & & & 34.0 & 10.9 & 34.1 & 13.4 & 37.1 & 19.3 \\
\hline 5 & -- & & & & & & & & & -- & 37.5 & 10.8 & 38.4 & 15.3 & 37.8 & 16.3 \\
\hline 6 & -- & & -- & & -- & -- & & - & -- & -- & 42.2 & 8.4 & 39.1 & 13.5 & 42.1 & 14.2 \\
\hline 7 & & & & & & & & & & & 44.5 & 5.2 & 41.9 & 9.9 & 41.2 & 10.6 \\
\hline 8 & & & & & & & & & & & 45.2 & 4.8 & 45.6 & 7.7 & 45.6 & 9.6 \\
\hline 9 & & & & & & & & & & & 48.8 & 2.9 & 48.3 & 5.8 & 50.1 & 7.5 \\
\hline 10 & & & & & & & & & & & 54.4 & 3.1 & 52.6 & 3.5 & 56.2 & 2.7 \\
\hline Total & & & & & & & & & & & 37.6 & 11.0 & 38.8 & 13.4 & 40.3 & 15.1 \\
\hline
\end{tabular}

Fuente: Elaboración propia, basada en datos de la EPH.

a Excluye a hogares que no responden total o parcialmente a la pregunta sobre ingresos. Incluye a los hogares sin ingresos. 
Destacan, por otro lado, que la contracción de la tasa de ocupación a tiempo completo (de $2.7 \%$ de la población urbana) entre 1992 y 1998 es en buena medida atribuible a la reducción de la tasa de empleo manufacturero $(-2.1 \%)$ y del comercio (-1\%) ocurrida en ese período.

Durante el último cuarto del siglo XX los salarios se establecieron bajo diferentes regímenes. A partir de 1976, las negociaciones colectivas estuvieron suspendidas y el gobierno fijó los salarios. En 1987 se restablecieron dichas negociaciones. En 1991 se introdujeron reformas para impulsar las negociaciones descentralizadas, por empresas, con poco éxito (Marshall, 2002).

El nivel real del salario alcanzó un máximo en 1974, culminando una tendencia al ascenso que llevaba más de una década (gráfico 4). Luego sufrió caídas de $14 \%$ en 1975 y $36 \%$ en 1976, esta última como consecuencia de la política de estabilización que congeló los salarios, devaluó el peso y liberalizó los precios. Posteriormente se fue recuperando hasta alcanzar en 1980 un nivel cercano al de 1975. En un escenario de nuevas y amplias oscilaciones de las remuneraciones, en 1986 el promedio fue más de 7\% inferior al de 1980. La hiperinflación y recesión de fines de los ochenta y
GRAFICO 4

Argentina: Evolución del salario real

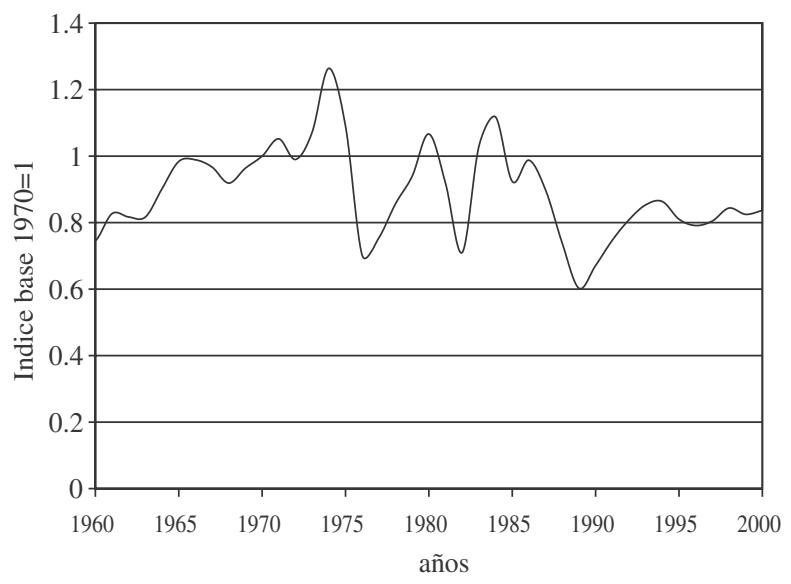

Fuente: Para 1960-1974 véase: Llach y Sánchez (1984); para 19742000 véanse datos de la EPH (Gran Buenos Aires).

principios de los noventa arrastraron el valor real del salario a un mínimo absoluto, $37 \%$ por debajo del nivel de 1980. La recuperación y posteriores oscilaciones, en un contexto de estabilidad de precios, han mantenido al salario real fluctuando entre $20 \%$ y $25 \%$ por debajo de aquel nivel (cuadro 1 y gráfico 4).

\section{IV}

\section{Impacto de los cambios en el mercado de trabajo sobre la distribución del ingreso familiar}

En vista del alto grado en que los ingresos laborales determinan la distribución del ingreso de los hogares y su evolución, optamos por una aproximación cuantitativa que permitiera descomponer la influencia de diferentes variables del mercado de trabajo sobre los cambios en la desigualdad de la distribución del ingreso de los hogares, recurriendo para ello al análisis de microsimulación. Con esa herramienta, se cuantifica el efecto de los cambios en la oferta de trabajo, el desempleo y las remuneraciones relativas. Estos últimos se analizan más en detalle mediante el análisis de regresión convencional.

\section{Análisis de microsimulación}

La técnica de microsimulación consiste en simular, para cada individuo de la población en edad activa del período $t$, la situación laboral (actividad/pasividad, empleo/desempleo, categoría ocupacional, sector de actividad, nivel educativo, remuneración) que habría tenido en el momento $t+k$ si hubiera sufrido los cambios que registraron las variables laborales consideradas ${ }^{21}$ entre $t$ y $t+k$, de acuerdo con las características sociodemográficas que cada individuo tenía en $t$. Alimentando los hogares correspondientes con los ingresos de esta población contrafáctica, se puede simular la distribución del ingreso de los hogares en $t+k$.

Esta técnica permite evaluar los cambios en toda la distribución del ingreso - recurriendo a poblaciones

\footnotetext{
${ }^{21}$ En el caso de Argentina, el análisis debe limitarse a los cambios en el mercado de trabajo que se registren en términos de las características laborales y de ingresos investigadas por la EPH.
} 
contrafácticas microsimuladas y asignando a cada observación el cambio que le correspondería de acuerdo con funciones de comportamiento estimadas sobre la base de los propios microdatos- y cuantificar el efecto de todas las variables explicativas consideradas (de manera alternativa o secuencial). ${ }^{22}$ Este procedimiento contrasta con los métodos corrientes de descomposición de los cambios en alguna medida sumaria de desigualdad (o de pobreza) para determinar qué proporción de éstos corresponde a cambios en las relaciones entre ingresos medios de diferentes subgrupos de la población, a la variación de la importancia relativa de cada subgrupo o a cambios de la distribución dentro de cada subgrupo, atribuibles por lo tanto a factores diferentes de la variable que sirviera para particionar la población con miras a la descomposición. ${ }^{23}$

En nuestro caso, el procedimiento consistió en simular, secuencialmente, poblaciones contrafácticas - de hombres y mujeres - que replicaran en la población de $t$ los valores registrados en $t+k$ por: las tasas de participación; las de participación y de desempleo; las dos variables anteriores y la estructura educacional de los ocupados; y, por último, esta estructura de la fuerza de trabajo, con remuneraciones calculadas aplicando los coeficientes de las funciones de ingreso de $t+k$ estimados por regresión. En las tres primeras simulaciones se asignaron ingresos a los individuos que habrían cambiado de categoría, ya sea para incorporarlos a la población simulada con ingresos laborales o para cambiar su ingreso como consecuencia del cambio de categoría educacional. En cada simulación se computaron los ingresos familiares que hubieran resultado de combinar los ingresos de la población contrafáctica, lo cual permite obtener una distribución simulada del ingreso de los hogares y calcular las correspondientes medidas de concentración y de pobreza. El análisis del efecto entre $t$ y $t+k$ de cada cambio considerado se realiza comparando, por un lado, la

\footnotetext{
${ }^{22}$ Para más detalles sobre el método de microsimulaciones aplicado a la dinámica de la distribución del ingreso, véase Bourguignon, Fournier y Gourgand (1998) y Bourguignon, Ferreira y Lustig (2001). ${ }^{23}$ Véase en Altimir y Beccaria (2000a) un ejercicio de descomposición de los cambios en el índice de Theil de la distribución de las remuneraciones horarias de los ocupados a tiempo completo, para el Gran Buenos Aires (1974/1997) y para un conjunto mayor de aglomeraciones urbanas (1991/1997), según cinco particiones alternativas (características) de esa población. Asimismo, en Altimir y Beccaria (1998) se efectuó la descomposición de los cambios en la incidencia agregada de la pobreza absoluta en el Gran Buenos Aires (1974/1997), identificando las variaciones de esa medida atribuibles a los cambios experimentados por la composición de los jefes de hogar o de los hogares, de acuerdo con diferentes atributos.
}

desigualdad de la distribución simulada con el cambio y, por otro, la desigualdad de la distribución simulada sin esa modificación (anterior en la secuencia de simulaciones).

Como se detalla en el apéndice metodológico, el primer paso consistió en estimar -mediante el método de máxima verosimilitud - un modelo Logit policotómico de participación en el mercado de trabajo, para hombres y mujeres y para cada año, que determinará la probabilidad de cada persona de la población en edad activa de estar inactiva, desempleada u ocupada, en función de su edad, estado civil, años de educación formal, si es o no jefe de familia, si tiene hijos menores (en el caso de las mujeres) y si asiste a un establecimiento educacional. Sobre esta base, y ordenando las personas de acuerdo con esas probabilidades, fue posible simular para cada año $t+k,{ }^{24}$ quiénes en la muestra habrían pasado a estar activos o inactivos (dependiendo de la variación agregada de la tasa de participación del género entre $t \mathrm{y} t+k$ ), desocupados u ocupados (según la variación en las tasas de desempleo).

El segundo paso fue estimar funciones de ingreso laboral para hombres y mujeres y para cada año, dependiendo de la edad (como variable sustitutiva de la experiencia), la edad al cuadrado y cinco variables ficticias correspondientes a los distintos niveles de educación formal. ${ }^{25}$ Sobre esa base fue posible imputar una remuneración a las personas que pasaron a estar ocupadas.

La comparación de la distribución original del año $t$ con la distribución simulada a partir de la población contrafáctica que se generó con la tasa de participación de $t+k$ permite cuantificar el efecto del cambio experimentado por esa variable sobre la distribución del ingreso familiar. Asimismo, la comparación de esta última distribución con la distribución simulada a partir de la población contrafáctica generada con las tasas de participación y desempleo de $t+k$ permite apreciar el efecto adicional del cambio en el desempleo. ${ }^{26}$

\footnotetext{
${ }^{24}$ Se realizó el ejercicio para los años 1980 (a ser comparado con 1974), 1986, 1990, 1994 y 2000, seleccionados por las razones analíticas ya señaladas.

${ }^{25}$ Primaria completa, secundaria incompleta, secundaria completa, universitaria incompleta y universitaria completa. Asimismo, la función de ingreso laboral incluyó el término de corrección del sesgo de la selección muestral de la ecuación [8] del apéndice, que captura la probabilidad de estar empleado, dadas las características sociodemográficas del trabajador.

${ }^{26}$ Naturalmente, al comparar la distribución generada con ambas tasas cambiadas con la distribución registrada en $t$ se obtiene una medida del efecto combinado de ambos cambios sobre la distribución del ingreso.
} 
Para cuantificar el efecto del cambio en la estructura educacional, se ordenó la población contrafáctica generada con las tasas de participación y desempleo de $t+k$, dentro de cada género y condición de actividad, de acuerdo con su nivel educacional en $t$. Como no se modeló la probabilidad de contar con un nivel educativo determinado, se ordenaron las personas dentro de cada grupo y nivel de acuerdo con un número aleatorio previamente asignado. Este ordenamiento permitió elegir qué personas ingresan y cuáles salen de cada nivel educacional, de acuerdo con el cambio agregado de la estructura entre $t$ y $t+k$. A las personas que cambian de categoría educacional se les corrigió la remuneración de acuerdo con la relación, en el año $t$, entre los ingresos medios de la nueva categoría y los de la categoría de origen.

A esta última población contrafáctica se le asignaron las remuneraciones que hubiera tenido en $t+k$, para apreciar el efecto adicional del cambio de las remuneraciones sobre la distribución del ingreso. Esto se hizo utilizando las funciones de ingreso laboral mensual estimadas, para cada año y para cada género, y asignando los coeficientes estimados para el año $t+k$ en lugar de los de $t$.

La comparación entre la población contrafáctica con las remuneraciones estimadas para $t+k$ y la misma población con las remuneraciones de $t$ permite apreciar el efecto del cambio de la estructura de remuneraciones. $^{27}$

\section{Factores determinantes de los cambios en la desigualdad}

Tal como fue diseñado, el ejercicio de microsimulaciones secuenciales consiste en comparar el valor de un indicador de la concentración de la distribución de los ingresos de los hogares -en nuestro caso, el coeficiente de Gini de la distribución del ingreso per cápita- del principio del período, con los valores de aquéllos correspondientes a las distribuciones que resultarían de diferentes poblaciones en edad activa contrafácticas — de hombres y mujeres, simuladas por separado-generadas al ir reemplazando, en una secuencia acumulativa, la tasa de actividad, el desempleo, la estructura educacional y las remuneraciones observadas al final del período, pero manteniendo constan-

27 Tal como se refleja en el ingreso laboral mensual, que a su vez está determinado por el ingreso horario y la cantidad de horas trabajadas, además del eventual aporte de una ocupación secundaria. tes las demás características de la población al principio del período. Las microsimulaciones realizadas tienen un margen de error atribuible a que las remuneraciones para quienes no están empleados y para quienes cambiaron de nivel educativo se obtuvieron a partir de generar un disturbio aleatorio. Por lo tanto, las simulaciones se repitieron 1000 veces, en un ejercicio Montecarlo, para poder establecer intervalos de confianza en la estimación de las medidas de desigualdad y de pobreza.

El ejercicio permite, por lo tanto, apreciar el efecto que diferentes cambios en la situación del mercado de trabajo tienen sobre la distribución del ingreso familiar en el Gran Buenos Aires, para distintos subperíodos del último cuarto del siglo $\mathrm{XX}{ }^{28}$

El cuadro 4 resume esos cambios, en función del indicador de la desigualdad de las distribuciones contrafácticas de los hogares ${ }^{29}$ Así, el valor incluido en la fila "Cambio en la participación" es el coeficiente de Gini de la distribución que hubiera prevalecido si la tasa de actividad hubiera sido la del año final del subperíodo, en lugar de la del año inicial del mismo. A continuación se indica el coeficiente de Gini de la distribución de los hogares que hubiera existido si se hubieran registrado, al inicio del subperíodo, las tasas de participación y de desempleo que imperaron al final del subperíodo; y así sucesivamente, incorporando asimismo los cambios de la estructura educacional y de las remuneraciones.

El cuadro 5 muestra los efectos de cada uno de esos cambios, en la secuencia en que ellos fueron simulados, en términos de puntos de variación del coeficiente de Gini entre las sucesivas poblaciones contrafácticas, para cada uno de los subperíodos. La diferencia entre el coeficiente de Gini de la distribución que incorpora

\footnotetext{
${ }^{28}$ El ejercicio se limitó al Gran Buenos Aires para poder abarcar comparativamente los diferentes subperíodos identificados como pertinentes en un lapso tan prolongado, dado que los microdatos disponibles para el interior del país se refieren sólo a los años noventa.

${ }^{29}$ Se incluyen los intervalos de confianza al $95 \%$ de la estimación de cada coeficiente, calculados mediante un procedimiento Montecarlo que incluyó 1000 simulaciones de cada cual. Estos intervalos permiten establecer si el efecto de cada variable (representado por la diferencia entre el coeficiente de Gini medio estimado cambiando los valores de la variable al final del período y el estimado con los valores al inicio del período) sobre la desigualdad es estadísticamente significativo. Ello se establece sobre la base de probar la hipótesis de que la diferencia entre ambos coeficientes de Gini sea nula, o sea, que el coeficiente de Gini estimado sin alterar la variable caiga dentro del intervalo de confianza de la estimación del Gini una vez alterada la variable, en cuyo caso la diferencia (e efecto de esa variable) no es estadísticamente significativa.
} 
CUADRO 4

Argentina: Estimaciones de la desigualdad de ingresos del hogar per cápita en sucesivas poblaciones contrafácticas, para distintos períodos ${ }^{a b}$

(Coeficientes de Gini)

\begin{tabular}{|c|c|c|c|c|c|}
\hline Período & $1974-80$ & $1980-86$ & $1986-90$ & $1990-94$ & $1994-2000$ \\
\hline $\begin{array}{l}\text { Coeficiente observado al inicio } \\
\text { del período }\end{array}$ & 0.367 & 0.394 & 0.419 & 0.459 & 0.482 \\
\hline Cambio en participación & $\begin{array}{c}0.360 \\
(0.359,0.360)\end{array}$ & $\begin{array}{c}0.400 \\
(0.399,0.403)\end{array}$ & $\begin{array}{c}0.411 \\
(0.409,0.413)\end{array}$ & $\begin{array}{c}0.455 \\
(0.453,0.458)\end{array}$ & $\begin{array}{c}0.468 \\
(0.465,0.471)\end{array}$ \\
\hline Cambio en participación y desempleo & $\begin{array}{c}0.360 \\
(0.359,0.361)\end{array}$ & $\begin{array}{c}0.438 \\
(0.437,0.440)\end{array}$ & $\begin{array}{c}0.416 \\
(0.412,0.418)\end{array}$ & $\begin{array}{c}0.469 \\
(0.467,0.473)\end{array}$ & $\begin{array}{c}0.469 \\
(0.466,0.472)\end{array}$ \\
\hline $\begin{array}{l}\text { Cambio en participación, desempleo } \\
\text { y estructura educacional }\end{array}$ & $\begin{array}{c}0.360 \\
(0.359,0.362)\end{array}$ & $\begin{array}{c}0.403 \\
(0.401,0.407)\end{array}$ & $\begin{array}{c}0.415 \\
(0.413,0.418)\end{array}$ & $\begin{array}{c}0.457 \\
(0.452,0.463)\end{array}$ & $\begin{array}{c}0.463 \\
(0.459,0.467)\end{array}$ \\
\hline $\begin{array}{l}\text { Cambio en participación, desempleo, } \\
\text { estructura educacional y remuneraciones }\end{array}$ & $\begin{array}{c}0.378 \\
(0.377,0.378)\end{array}$ & $\begin{array}{c}0.395 \\
(0.394,0.396)\end{array}$ & $\begin{array}{c}0.434 \\
(0.432,0.435)\end{array}$ & $\begin{array}{c}0.470 \\
(0.465,0.474)\end{array}$ & $\begin{array}{c}0.493 \\
(0.490,0.496)\end{array}$ \\
\hline Coeficiente observado al final del período & 0.394 & 0.419 & 0.459 & 0.482 & 0.510 \\
\hline
\end{tabular}

Fuente: Elaboración propia, basada en datos de la EPH.

a Las cifras en cursivas son estimaciones cuya diferencia con la estimación anterior, en la secuencia, no es estadísticamente significativa al $95 \%$

b Las cifras entre paréntesis indican intervalos de confianza, al 95\%, de las estimaciones del coeficiente de Gini correspondientes a las distribuciones simuladas.

CUADRO 5

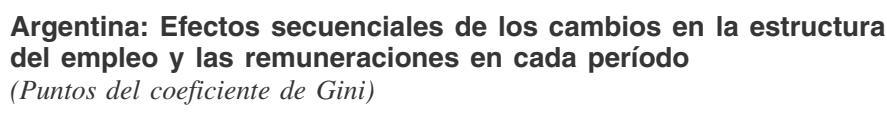

Argentina: Efectos secuenciales de los cambios en la estructura del empleo y las remuneraciones en cada período

(Puntos del coeficiente de Gini)

\begin{tabular}{|c|c|c|c|c|c|}
\hline Período & $1974-80$ & $1980-86$ & $1986-90$ & $1990-94$ & $1994-2000$ \\
\hline Coeficiente de Gini al inicio del período & 0.367 & 0.394 & 0.419 & 0.459 & 0.482 \\
\hline Efecto participación & -0.007 & 0.006 & -0.008 & -0.004 & -0.014 \\
\hline Efecto desempleo & $\ldots{ }^{\mathrm{a}}$ & 0.038 & 0.005 & 0.014 & $\ldots$ \\
\hline Efecto estructura educacional & $\ldots$ & -0.035 & $\ldots$ & -0.012 & -0.006 \\
\hline Efecto remuneraciones & 0.018 & -0.008 & 0.019 & 0.013 & 0.030 \\
\hline Cambio no explicado & 0.016 & 0.024 & 0.025 & 0.012 & 0.017 \\
\hline Coeficiente de Gini al final del período & 0.394 & 0.419 & 0.459 & 0.482 & 0.510 \\
\hline Variación de la desigualdad & 0.027 & 0.025 & 0.040 & 0.023 & 0.028 \\
\hline
\end{tabular}

Fuente: Elaboración propia, basada en datos de la CEPAL y de la EPH.

a (...) indica que es estadísticamente no significativo al $95 \%$.

todos los cambios considerados y el efectivamente registrado al final del subperíodo constituye la parte de las variaciones en la concentración efectiva del ingreso per cápita que no es explicada mediante este modelo del mercado de trabajo; corresponde, por lo tanto, al efecto de cambios en otros factores, algunos tam- bién relacionados con el trabajo - como la rama de actividad o la categoría ocupacional - y otros ajenos a él, como los ingresos no laborales o el tamaño y composición de los hogares. De acuerdo con los valores del cuadro 5, estos factores tuvieron una influencia importante — similar a la del conjunto de los fac- 

del empleo y las remuneraciones sobre la distribución del ingreso de los hogares (Puntos de Gini)

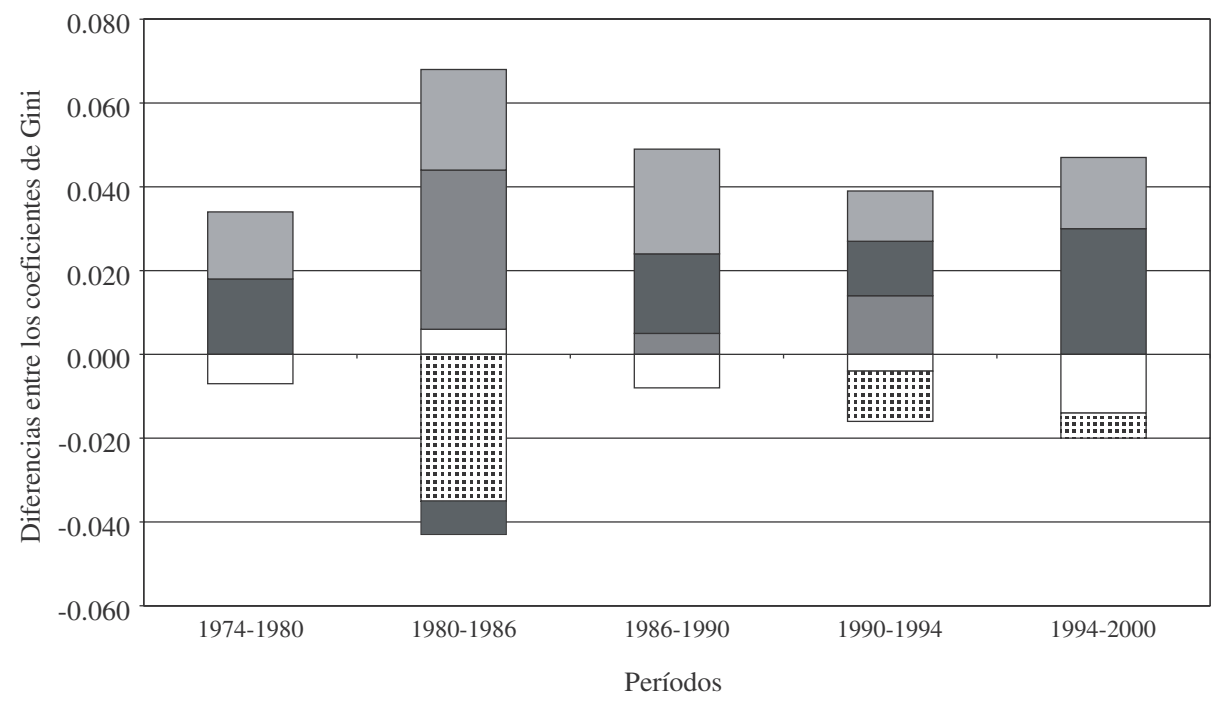

$\square$ Efecto participación $\square$ Efecto desempleo $\quad$ 围 Efecto estructura educacional
$\square$ Efecto remuneraciones $\square$ Cambio no explicado

Fuente: Elaboración propia, basada en datos de la EPH (Gran Buenos Aires).

tores considerados en el modelo de simulación- sobre el aumento de la desigualdad. ${ }^{30}$

El cambio en las tasas de participación ha tenido un efecto casi siempre favorable a una menor desigualdad, aunque de magnitud secundaria. El aumento del desempleo, en cambio, ha tenido una influencia perniciosa, particularmente notable en los subperíodos 19801986 y 1990-1994. El cambio en la estructura educacional ha ejercido un permanente efecto igualador, aunque de importancia variable. El cambio en las remuneraciones ha contribuido en casi todos los subperíodos y de manera importante al aumento de la desigualdad (gráfico 5).

\footnotetext{
${ }^{30} \mathrm{Sin}$ embargo, estos otros factores relacionados con el trabajo parecen haber tenido una importancia secundaria. En un ejercicio similar de microsimulación para el período 1991-1998, Frenkel y González Rozada (2000) consideran también el efecto de los cambios en la estructura del empleo por sector de actividad. Esos cambios, simulados por esos autores después de considerar los cambios en las tasas de participación y de desempleo y antes de considerar las modificaciones en la estructura educacional, habrían ejercido un efecto de baja magnitud en favor de una menor desigualdad.
}

En los años setenta, a partir de 1974, más de la mitad de ese aumento puede atribuirse al cambio en las remuneraciones relativas (cuadro 5), cuyo efecto fue compensado sólo parcialmente por el del cambio en las tasas de actividad, que disminuyeron significativamente entre los hogares de los deciles superiores de la distribución. Entre 1980 y 1986, en cambio, un aumento de la desigualdad de parecida magnitud resulta escasamente explicado por las modificaciones en el mercado de trabajo consideradas en el modelo. El efecto del notable aumento que durante este período registró el desempleo en los primeros deciles de la distribución del ingreso (cuadro 3) fue contrarrestado por el impacto igualador de los cambios en la estructura educacional; ${ }^{31}$ de la misma forma, la leve influencia desigualadora de los cambios en las tasas de participación fue compensada por un influjo en sentido contrario de las remuneraciones. Entre 1986 y 1990 la

\footnotetext{
${ }^{31}$ En este período, la población ocupada sin educación o hasta con educación primaria incompleta pasó de $16 \%$ a $11.6 \%$, mientras que los ocupados con educación secundaria completa o terciaria incompleta pasaron de $22 \%$ a $26.4 \%$.
} 
Argentina: Evolución de la ocupación por nivel educativo (Indice base 1991=100)

\begin{tabular}{|c|c|c|c|c|c|c|c|}
\hline & 1974 & 1980 & 1986 & 1991 & 1994 & 1997 & 2000 \\
\hline Total de aglomeraciones urbanas & - - & -- & -- & 100.0 & 101.3 & 108.6 & 114.1 \\
\hline Hasta primario incompleto & - - & -- & -- & 100.0 & 81.9 & 82.6 & 66.1 \\
\hline Primario completo & -- & -- & -- & 100.0 & 98.0 & 96.2 & 94.0 \\
\hline Secundario incompleto & - - & $-{ }_{-}$ & -- & 100.0 & 102.4 & 111.6 & 113.2 \\
\hline Secundario completo & -- & -- & -- & 100.0 & 105.3 & 110.1 & 127.3 \\
\hline Superior y universitario incompleto & -- & -- & -- & 100.0 & 106.0 & 135.7 & 153.2 \\
\hline Superior y universitario completo & -- & -- & -- & 100.0 & 117.9 & 136.5 & 162.0 \\
\hline Gran Buenos Aires & 82.5 & 87.6 & 93.5 & 100.0 & 100.3 & 107.1 & 110.3 \\
\hline Hasta primario incompleto & 193.0 & 146.5 & 126.6 & 100.0 & 76.0 & 80.6 & 65.3 \\
\hline Primario completo & 89.7 & 98.3 & 94.6 & 100.0 & 97.6 & 92.5 & 88.0 \\
\hline Secundario incompleto & 70.5 & 80.3 & 94.7 & 100.0 & 99.8 & 108.6 & 112.3 \\
\hline Secundario completo & 52.4 & 66.6 & 80.1 & 100.0 & 107.1 & 108.3 & 122.9 \\
\hline Superior y universitario incompleto & 57.7 & 71.9 & 84.3 & 100.0 & 106.9 & 142.4 & 145.7 \\
\hline Superior y universitario completo & 37.8 & 56.3 & 83.1 & 100.0 & 117.6 & 141.8 & 166.8 \\
\hline Interior & - - & -- & -- & 100.0 & 102.8 & 110.9 & 119.5 \\
\hline Hasta primario incompleto & -- & -- & -- & 100.0 & 89.4 & 85.0 & 67.2 \\
\hline Primario completo & & & & 100.0 & 98.6 & 102.7 & 104.1 \\
\hline Secundario incompleto & - - & -- & $-{ }_{-}$ & 100.0 & 106.1 & 116.0 & 114.5 \\
\hline Secundario completo & -- & -- & -- & 100.0 & 102.5 & 112.9 & 134.1 \\
\hline Superior y universitario incompleto & -- & -- & -- & 100.0 & 104.9 & 127.1 & 162.0 \\
\hline Superior y universitario completo & & & & 100.0 & 118.3 & 129.9 & 156.1 \\
\hline
\end{tabular}

Fuente: Elaboración propia, basada en datos de la EPH.

desigualdad en la distribución del ingreso familiar per cápita aumentó casi tanto como en los dos períodos anteriores. Alrededor de la mitad de ese aumento se explica por la mayor dispersión de las remuneraciones relativas según niveles de educación, en tanto que el efecto igualador de los cambios en las tasas de actividad fue prácticamente contrarrestado por el influjo negativo del aumento en el desempleo.

Entre 1990 y 1994 la desigualdad de los ingresos familiares sufrió un nuevo y significativo incremento. Sólo la mitad de ese empeoramiento obedeció a cambios en el mercado de trabajo, como resultado de: i) el espectacular aumento del desempleo en los estratos de menores ingresos (cuadro 3); ii) la ampliación de las diferencias en las remuneraciones por niveles de educación y, en sentido contrario, iii) el continuo cambio en la estructura educacional de los perceptores. El aumento de las tasas de actividad, que alcanzaron en 1994 niveles sin precedentes, fue muy generalizado y tuvo, por lo tanto, escaso efecto sobre la desigualdad de los ingresos.

El ulterior incremento de la desigualdad ocurrido entre 1994 y 2000 también se explica parcialmente por cambios en el mercado de trabajo: i) una considerable ampliación - mayor que en cualquier subperíodo anterior- de las diferencias de ingreso por niveles de educación, sólo parcialmente compensada por ii) el efecto de una nueva elevación en las tasas de actividad, comparativamente más intensa entre los hogares de bajos ingresos, y iii) el consabido efecto igualador de los cambios en la estructura educacional de los perceptores, entre quienes continuó aumentando la proporción de aquéllos con educación media y alta (cuadro 6).

\section{Las remuneraciones unitarias y las horas tra- bajadas}

El ingreso considerado en las simulaciones arriba analizadas corresponde al ingreso laboral mensual de los ocupados. Sus efectos sobre la distribución de los ingresos familiares combinan tanto el de los cambios en la desigualdad de las remuneraciones unitarias como el de las variaciones en las diferencias de horas trabajadas. Sólo en algunos períodos éstas han ejercido algún efecto significativo, a veces atenuando la desigualdad de las remuneraciones unitarias y otras veces agudizándola. Entre 1974 y 1980, la mejora en la distribución de las horas trabajadas atenuó el considerable aumento de la desigualdad registrado por las remuneraciones horarias. Lo contrario ocurrió entre 1980 y 1986, cuando una disminución de la desigualdad de los 


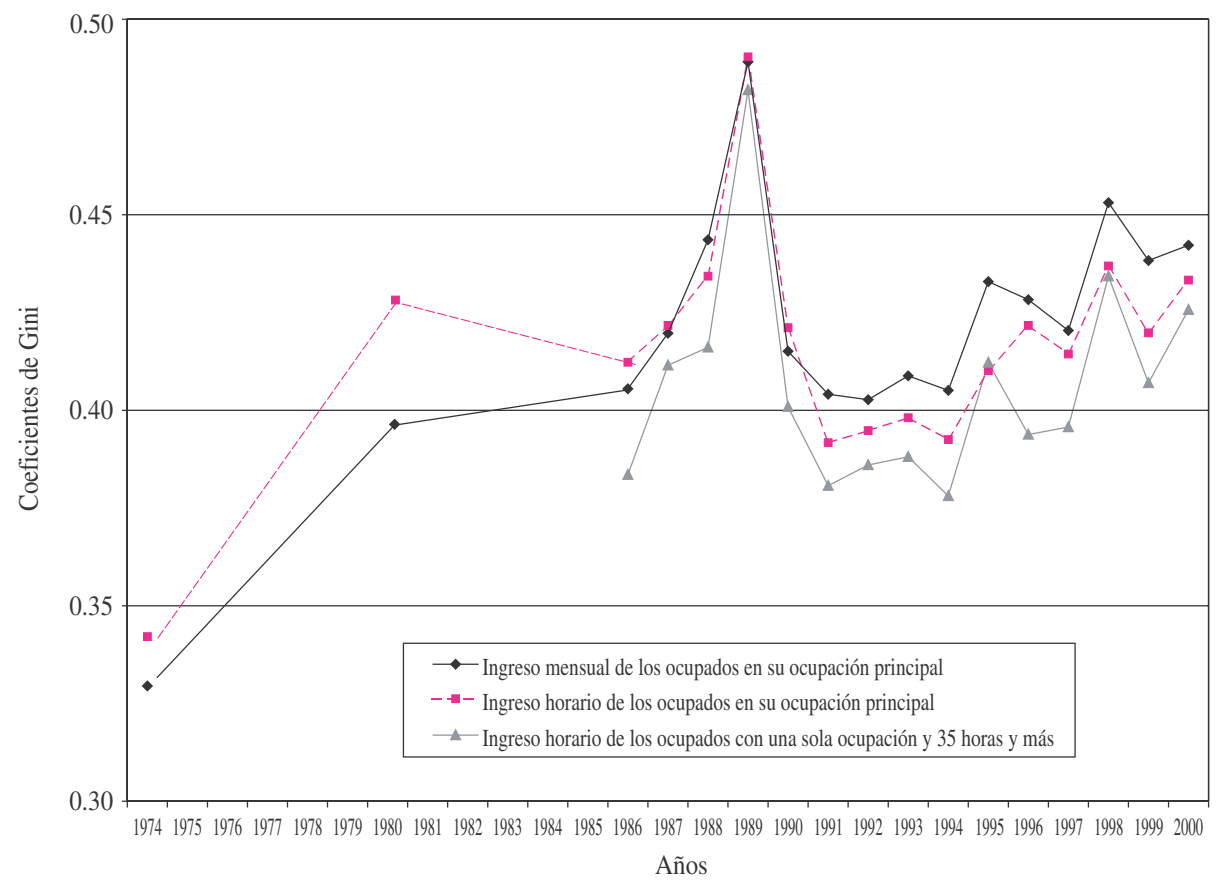

Fuente: Elaboración propia, basada en datos de la EPH.

ingresos horarios se convirtió en un moderado aumento de la desigualdad de los ingresos mensuales (gráfico 6). Asimismo, la significativa reducción de la desigualdad de los ingresos horarios acaecida entre 1990 y 1991 resultó en una más ligera disminución de la desigualdad de los ingresos mensuales, por la ampliación de la disparidad en las horas trabajadas por miembros de diferentes estratos de ingreso. Por el contrario, los cambios en esta intensidad diferencial del trabajo atenuaron los aumentos de la desigualdad de ingresos horarios en 1996 y en 2000. En definitiva, los cambios en las diferencias de ingresos horarios han establecido — en lo esencial - la tendencia de la distribución de los ingresos personales de los perceptores ocupados (gráfico 6).

Sin embargo, la distribución de los ingresos horarios abarca todo tipo de ocupaciones de diferente duración e incluye, por lo tanto, situaciones de subempleo voluntario y también involuntario que, como vimos, fueron en aumento durante los años noventa. Por tal razón analizamos además cómo evolucionó la distribución de los ingresos horarios de los ocupados con una sola ocupación que trabajan por lo menos 35 horas semanales: este es el concepto de la encuesta que más se aproxima a la remuneración unitaria de los empleos de tiempo completo. Más allá de una mayor y natural variabilidad, la tendencia que exhibe la concentración de esa distribución, entre los años seleccionados como de mayor normalidad macroeconómica relativa (gráfico 6), es aún más nítida que la exhibida por la concentración de la distribución de todas las remuneraciones horarias: un coeficiente de Gini de 0.38 en 1986, 1991 y 1994, que se eleva a casi 0.40 en 1997, aunque luego salta a 0.44 , ya en la primera fase de la actual recesión.

\section{Los factores determinantes de los cambios en las remuneraciones relativas}

Bajo esta evolución de la desigualdad de las remuneraciones horarias pueden subyacer cambios - a veces contrapuestos - de los diferenciales de remuneración según las distintas características de los ocupados, que pueden revelar la influencia que han ejercido, entre períodos, variables de la oferta y de la demanda de trabajo. En procura de evidencias de esta índole se 
Gran Buenos Aires: Funciones de ingreso, años seleccionados ${ }^{\text {ab }}$

(Variable dependiente: logaritmo de la remuneración horaria en la ocupación principal)

\begin{tabular}{|c|c|c|c|c|c|c|c|}
\hline Categorías & 1974 & 1980 & 1986 & 1990 & 1994 & 1997 & 2000 \\
\hline \multicolumn{8}{|l|}{ Educación } \\
\hline Primaria completa & -0.1318178 & -0.1860587 & -0.1654524 & -0.1574174 & -0.1368625 & -0.2008298 & -0.1820582 \\
\hline Secundaria incompleta & 0.1674785 & 0.1476424 & 0.2028399 & 0.1513331 & 0.2252899 & 0.1848086 & 0.1665152 \\
\hline Secundaria completa & 0.3589101 & 0.5126224 & 0.4044073 & 0.4949932 & 0.4127261 & 0.4530148 & 0.4450138 \\
\hline Terciaria incompleta & 0.4276585 & 0.657878 & 0.646664 & 0.7833223 & 0.669927 & 0.6419327 & 0.6814434 \\
\hline Terciaria completa & 0.8239498 & 1.042674 & 0.9171951 & 0.9802195 & 0.9826189 & 1.08574 & 1.149472 \\
\hline \multicolumn{8}{|l|}{ Características individuales } \\
\hline Género & 0.3736265 & 0.343417 & 0.2720114 & 0.201527 & 0.1710177 & 0.1896878 & 0.2040489 \\
\hline Edad & 0.0418729 & 0.0469294 & 0.0552483 & 0.0494946 & 0.0478113 & 0.0450942 & 0.0438228 \\
\hline Edad $^{2}$ & -0.0004466 & -0.0004912 & -0.0005819 & -0.0004927 & -0.0004959 & -0.0004092 & -0.0003891 \\
\hline \multicolumn{8}{|l|}{ Sectores de actividad } \\
\hline Construcción & $-0.0493249^{c}$ & $-0.029007^{\mathrm{c}}$ & -0.1515462 & $-0.1601648^{d}$ & $0.0064477^{\mathrm{c}}$ & $0.0028718^{\mathrm{c}}$ & $-0.012539^{c}$ \\
\hline Comercio & -0.1575408 & $-0.0511649^{\mathrm{e}}$ & -0.1715423 & -0.1603177 & -0.1629117 & -0.259589 & -0.2428781 \\
\hline Transporte y finanzas & $-0.022376^{\mathrm{c}}$ & $0.0679954^{\mathrm{e}}$ & $0.047942^{\mathrm{c}}$ & $0.0532897^{\mathrm{c}}$ & $-0.0119688^{c}$ & $-0.0496745^{\mathrm{c}}$ & -0.1161936 \\
\hline Administración pública & $0.1287654^{d}$ & $0.0014316^{\mathrm{c}}$ & $-0.0855258^{c}$ & -0.2636433 & $0.0670934^{c}$ & $-0.0076822^{c}$ & $0.070859^{c}$ \\
\hline Otros servicios & -0.1911927 & $-0.0769389^{d}$ & -0.126884 & -0.1847071 & $-0.0366766^{c}$ & -0.121029 & -0.0938155 \\
\hline \multicolumn{8}{|l|}{ Categoría ocupacional } \\
\hline Asalariados no registrados & -0.2526092 & -0.1478836 & -0.1049085 & -0.2737152 & -0.1390019 & -0.2548484 & -0.2722385 \\
\hline No asalariados & -0.0689237 & 0.1508761 & 0.1042153 & $-0.0804171^{d}$ & $0.0252879^{c}$ & -0.0822184 & -0.1526577 \\
\hline Constante & 1.172632 & 7.18064 & -1.225262 & 6.94072 & -0.2307537 & -0.2137342 & -0.2440764 \\
\hline $\mathrm{R}^{2}$ ajustado & 0.3555 & 0.3345 & 0.3508 & 0.2956 & 0.3038 & 0.3956 & 0.4057 \\
\hline $\mathrm{N}^{\circ}$ de observacioness & 3423 & 2836 & 3271 & 1914 & 2534 & 2642 & 2597 \\
\hline
\end{tabular}

Fuente: Elaboración propia, basada en datos de la EPH.

a Categorías excluidas: Educación: primaria completa; Posición en el hogar: no jefe; Sexo: mujeres; Rama: industria; Categoría ocupacional: asalariados registrados.

b Coeficientes de regresión significativos al 1\%, salvo indicación contraria.

c No significativo al $10 \%$.

d Significativo al $5 \%$.

e Significativo al $10 \%$.

estimaron funciones de ingreso "tipo Mincer" en las que el logaritmo de la remuneración horaria de ocupaciones principales de tiempo completo (de la muestra correspondiente a cada año seleccionado) se vincula con las características de los ocupados con una sola ocupación: nivel de educación, sector de actividad, ${ }^{32}$ categoría ocupacional, edad, género y jefatura del hogar (cuadro 7). Los coeficientes estimados para cada categoría de una característica — controlando por las demás - representan el "diferencial de remuneración" o "premio" de esa categoría con respecto a la que se toma como referencia.

La evolución de los diferenciales de remuneración por niveles educativos proporciona más información sobre las tendencias que imperaron en cada período,

32 Con la desagregación en cinco sectores admitida por el tamaño de la muestra. detrás del efecto desigualador que los cambios en la estructura de las remuneraciones al capital humano tuvieron sobre la distribución del ingreso de los hogares. Este efecto fue cuantificado en el ejercicio de simulación y se representa en el gráfico 5. A lo largo del último cuarto del siglo XX se incrementaron los premios correspondientes a los niveles educativos más elevados: secundario completo y terciario. Casi todos esos incrementos se registraron entre 1974 y 1980; al finalizar la década de crisis de los años ochenta y pese a la profunda caída (39\%, en promedio) de los ingresos horarios reales, los diferenciales entre niveles eran similares a los existentes en $1980 .{ }^{33}$ En 1994, cuando culminaba el período de recuperación y crecimiento, se habían debilitado los premios a las calificaciones

\footnotetext{
${ }^{33}$ La única alteración destacable es el aumento del premio a la educación terciaria incompleta y la reducción del correspondiente a la terciaria completa (cuadro 7).
} 
intermedias (secundaria completa y terciaria incompleta). Hacia 1997, el premio a la educación terciaria completa ya había superado el alcanzado en 1980, en tanto que los correspondientes a los demás niveles de educación se mantenían cercanos a los registrados entonces. Esta diferenciación se hizo mayor durante la recesión posterior, cuando los premios a la educación primaria completa y secundaria incompleta se redujeron y el correspondiente a la educación terciaria completa continuó aumentando (cuadro 7).

En las aglomeraciones urbanas del interior del país, los premios a la educación en los niveles superiores son de menor magnitud que los registrados en el Gran Buenos Aires. Durante toda la década de 1990, esto ha representado menores diferencias relativas de remuneraciones, lo que en alguna medida contribuye a explicar los menores niveles de desigualdad en la distribución del ingreso de los perceptores ocupados imperantes en el interior (gráfico 1).

Ya se destacó la importancia relativa del cambio que no se explica por los factores considerados en el ejercicio de simulación (gráfico 6). Una parte de ese efecto puede deberse a los cambios en las remuneraciones relativas de las categorías ocupacionales. Las ecuaciones del cuadro 7 muestran un significativo distanciamiento, entre 1974 y 1980, del ingreso de los no asalariados (principalmente trabajadores por cuenta propia) con respecto al de los asalariados registrados en el sistema de seguridad social, que se revierte en la década de 1980 y que termina por desembocar, a lo largo de los años noventa, en un diferencial negativo mayor al que existía en 1974. En lo que respecta a los asalariados no registrados, su ingreso diferencial (negativo) mejoró durante los años ochenta y también en 1994, volviendo a registrar a partir de 1997 el valor que tuvo en 1974.

Los cambios en los ingresos diferenciales de los diversos sectores de actividad también quedaron fuera del modelo explicativo del ejercicio de simulación. Sin embargo, su influencia en la evolución de la desigualdad aparece más difusa. Entre los cambios significativos resaltan: el retroceso del diferencial de salario de la administración pública (con respecto a la industria) entre 1974 y 1986, parcialmente revertido en los años noventa; el deterioro, a partir de 1997, del diferencial de comercio; y el mejoramiento del diferencial de otros servicios, en 1980 y nuevamente en 1994 (cuadro 7).

La diferencia de ingresos vinculada al género, favorable a los hombres, tendió a disminuir, esencialmente en el decenio de 1980, y luego a tornarse estacionaria en el de 1990. En cambio, el premio a la edad - entre los ocupados - se mantuvo estable a lo largo de todo el período considerado.

\section{V}

\section{Influencia de otros recursos sobre la distribución del ingreso de los hogares}

En lo esencial, la tendencia de la distribución del ingreso de los hogares está determinada por la evolución de la desigualdad de los ingresos laborales y de las oportunidades de obtenerlos ofreciendo tiempo y capital humano en el mercado de trabajo. Sin embargo, los miembros de los hogares poseen otros activos - fijos o financieros- que generan ingresos, así como derechos adquiridos a recibir transferencias en efectivo ${ }^{34}$

\footnotetext{
${ }^{34}$ La EPH no proporciona información suficiente para obtener estimaciones del valor de las transferencias recibidas en especie bajo la forma de servicios públicos gratuitos o altamente subsidiados (educación, salud, alimentos, etc.). Tampoco indaga sobre los ingresos
}

de los sistemas de protección social (pensiones, etc.). Los cambios en la distribución de estos ingresos no laborales pueden influir en la evolución de corto plazo de la concentración del ingreso de los hogares e incluso modificar la tendencia marcada por la evolución de los ingresos laborales.

Estos efectos pueden apreciarse indirectamente observando la evolución de la desigualdad de los

brutos antes del pago de contribuciones o descuentos. Por ambas circunstancias, el ingreso de los hogares cuya distribución se analiza en este trabajo tiende a ser la suma de los ingresos monetarios "de bolsillo" obtenidos por los miembros del hogar. 
Argentina: Desigualdad de características relevantes entre los quintiles extremos de la distribución del ingreso familiar per cápita (Valor medio del quinto quintil / valor medio del primer quintil)

\begin{tabular}{|c|c|c|c|c|c|c|c|}
\hline & 1974 & 1980 & 1986 & 1990 & 1994 & 1997 & 2000 \\
\hline Ingreso del hogar per cápita & 6.77 & 8.04 & 8.91 & 11.71 & 12.6 & 15.04 & 17.09 \\
\hline Proporción de jubilados & 1.34 & 1.24 & 1.09 & 1.14 & 1.50 & 2.05 & 3.08 \\
\hline Valor medio de las jubilaciones & 2.12 & 2.80 & 2.15 & 2.52 & 3.87 & 4.54 & 3.83 \\
\hline Proporción perceptores otros ingresos & 1.82 & 2.78 & 2.66 & 1.83 & 1.30 & 1.11 & 0.78 \\
\hline Valor medio otros ingresos por perceptor & 5.18 & 4.59 & 5.13 & 3.60 & 4.76 & 7.53 & 8.4 \\
\hline Proporción personas mayores de 15 años & 1.5 & 1.46 & 1.45 & 1.54 & 1.48 & 1.49 & 1.46 \\
\hline Tasa de actividad mayores 15 años & 1.74 & 1.52 & 1.60 & 1.72 & 1.43 & 1.29 & 1.28 \\
\hline Proporción de ocupados entre activos & 1.03 & 1.05 & 1.14 & 1.22 & 1.45 & 1.57 & 1.58 \\
\hline Tasa de empleo & 1.80 & 1.60 & 1.82 & 2.09 & 2.07 & 1.57 & 2.02 \\
\hline
\end{tabular}

Fuente: Elaboración propia, basada en datos de la EPH.

diferentes tipos de ingreso, como se hace en el cuadro 8 , sobre la base de las relaciones entre quintiles extremos de la distribución del ingreso de los hogares. En lo que respecta a las jubilaciones, si bien entre 1980 y 1986 se atenuaron las disparidades entre estratos, tanto en la proporción de jubilados como en el valor medio de las jubilaciones, posteriormente ellas se fueron ampliando. En conjunto, las jubilaciones gravitan regresivamente sobre la distribución agregada; por consiguiente, esa creciente disparidad entre estratos tuvo alguna influencia - moderada, en comparación con la de las variables laborales - sobre el aumento de la desigualdad de los hogares en los años noventa. ${ }^{35}$

También la evolución de los ingresos de la propiedad contribuyó a elevar la disparidad del ingreso de los hogares en los años noventa. De acuerdo con los datos de la EPH, ${ }^{36}$ entre 1994 y 1997 aumentó conside-

\footnotetext{
35 En un trabajo anterior (Altimir y Beccaria, 2000a) se efectuó la descomposición de diferentes medidas de desigualdad (la razón entre valores medios de quintiles extremos y el coeficiente de Gini) de acuerdo con un modelo de formación del ingreso del hogar per cápita, en términos de variables laborales y no laborales —como las del cuadro 8-, y se simuló alternativamente la desigualdad de la distribución agregada — en cada año- si no hubiera existido desigualdad de cada variable considerada en el modelo, evaluando así el efecto de ésta sobre la desigualdad total. El análisis de la influencia de los ingresos no laborales en este acápite se basa en esos resultados.

36 Se presume que la EPH subestima los ingresos de la propiedad en efectivo, tanto por la dificultad de incluir en la muestra a los pocos perceptores de estos ingresos, como por la subdeclaración y otros sesgos de respuesta que afectan la captación de ingresos no laborales. Por otro lado, una parte importante de las utilidades y otros ingresos de la propiedad generados en el proceso productivo queda institucional y contablemente apropiada dentro de las empresas, con lo que pasa directamente a formar parte de la riqueza de los propie-
}

rablemente el valor medio de este tipo de ingresos para los estratos superiores de la distribución, en comparación con los estratos más bajos (cuadro 8). Sin embargo, esta circunstancia, asociada en buena medida a la ampliación de los depósitos a plazo fijo, puede ser parcialmente ilusoria en un contexto de estabilidad de precios si la encuesta ha incluido ingresos de la propiedad que anteriormente no eran captados o cuyo lugar ocupaban ganancias de capital por aumento de valor de los activos. ${ }^{37}$

Por otro lado, las diferencias de la estructura demográfica de los hogares de distintos estratos — que, en general, favorecen a los ricos- contribuyen significativamente a la desigualdad: en órdenes de magnitud comparables a los de las diferencias en las tasas de actividad (Altimir y Beccaria, 2000a). Sin embargo, las variaciones de esta desigualdad, que se han mantenido relativamente estables en torno a una tendencia casi estacionaria, han influido poco en la evolución de la desigualdad entre los hogares. Quizá los efectos más significativos hayan sido el ejercido por el estrechamiento de las disparidades entre 1974 y 1980, que contribuyó a atenuar el aumento de la desigualdad en la distribución del ingreso per cápita de los hogares, y la ampliación temporaria de las diferencias en la dependencia demográfica registrada en 1988/ 1991, que tuvo el efecto contrario (cuadro 8).

tarios de las empresas, sin quedar registrada en el flujo de ingresos que éstos perciben como hogares. Por ambas razones, el análisis del efecto de los ingresos provenientes de la propiedad sobre la distribución agregada del ingreso, basándose en los datos de la EPH, resulta limitado y sesgado.

${ }^{37}$ Como, por ejemplo, la tenencia de dólares. 


\section{VI}

\section{El deterioro de la distribución del ingreso familiar}

En definitiva, como se observa en el gráfico 1, la evolución de la distribución del ingreso de los hogares ha estado fuertemente determinada por la de los ingresos laborales. Sin embargo, en dos oportunidades la desigualdad entre los hogares cambió en sentido opuesto a lo sucedido con la de los perceptores ocupados: en la primera, ese contraste se revirtió; en la segunda, se proyectó hacia adelante, determinando que la tendencia al aumento de la desigualdad fuera más acentuada entre los hogares que entre los perceptores ocupados. Entre 1974 y 1980, el considerable aumento de la disparidad de las remuneraciones y entre los perceptores se manifestó de manera muy atenuada en la distribución de los hogares, debido al emparejamiento de las tasas de participación entre estratos. Esta divergencia tendió a desaparecer entre 1980 y 1986, en parte debido a mayores disparidades en las tasas de participación pero sobre todo por el aumento del desempleo casi exclusivamente en los estratos inferiores (cuadro 3). En 1989, en plena hiperinflación, la desigualdad de los hogares "saltó" 0.037 puntos del coeficiente de Gini por encima de la desigualdad de los ocupados (en tanto que en el año anterior eran similares); posteriormente esa diferencia entre ambas series se mantuvo hasta que en 1994 volvió a ampliarse.

En 1989 aumentó la desocupación, pero el incremento nuevamente se concentró en los estratos inferiores, para los cuales la tasa se elevó por encima de $20 \%$, avanzando más de seis puntos porcentuales. En cambio, la reactivación inicial de 1990, que atenuó marginalmente el desempleo agregado, no disminuyó de manera significativa las altas tasas de desocupación de los estratos inferiores, en tanto que las tasas de actividad se diferenciaron aún más entre estratos (cuadro 3). ${ }^{38}$ Hacia 1994, los hogares de la mitad inferior

\footnotetext{
${ }^{38}$ Esta evolución queda disimulada en la descomposición que se realizó mediante el ejercicio de microsimulación, donde el efecto negativo (en el sentido de disminución de la desigualdad) del cambio en las tasas de participación entre 1986 y 1990 (cuadro 5) refleja el efecto de los cambios favorables entre 1986 y 1988, la virtual neutralidad de los habidos en 1989 y el efecto desigualador de los ocurridos en 1990; el efecto positivo (en el sentido de aumentar la desigualdad) de los cambios en el desempleo, en ese mismo período, tuvo lugar entre 1986 y 1988 y, sobre todo, en 1989.
}

de la distribución exhibieron tasas de desempleo muy altas, lo que amplió la desigualdad de esta distribución, alejándola más aún de la de los perceptores y empinando su tendencia ascendente. Como se observó en el ejercicio de microsimulación, en el período 19901994 el impacto desigualador de la desocupación fue contrarrestado sólo en pequeña medida por el efecto igualador de la participación, que se amplió significativamente en todos los estratos de ingreso, con poco efecto diferencial. De hecho, el comportamiento de la oferta de trabajo en este período, frente a la demanda existente, implicó una asociación entre el aumento de la tasa de participación ${ }^{39}$ (en el agregado, de $38.2 \%$ a $42.6 \%$ ) y el de la tasa de desempleo (de $6.6 \%$ a $13.4 \%$ de la población activa): el incremento de este último representó más de la mitad de la ampliación de la población activa, pero en los hogares por debajo del ingreso mediano la relación fue aún mayor, sugiriendo que, en la mayoría de esos casos, el paso de la inactividad a la búsqueda de trabajo fue infructuoso y, de acuerdo con los resultados de la microsimulación (gráfico 5), probablemente contribuyó de manera importante al aumento de la desigualdad entre los hogares, tal como la medimos. ${ }^{40}$ Entre 1994 y 1997 continuó aumentando la tasa de actividad (hasta $44.2 \%$ de la población) y elevándose el desempleo, ${ }^{41}$ que afectó a $14.7 \%$ de la ampliada fuerza de trabajo; nuevamente, el aumento de la desocupación representó más de la mitad de la expansión de la población activa, pero ese fenómeno se produjo irregularmente, a través de toda la pirámide de ingresos, por lo que tuvo escasas consecuencias distributivas (cuadro 3). En el año 2000, en

\footnotetext{
${ }^{39}$ Más intenso entre las mujeres y los jóvenes (Altimir y Beccaria, 2000b).

40 Desde otra perspectiva, el hecho de que miembros del hogar anteriormente pasivos sin ingresos se vuelvan activos pero desocupados, igualmente sin ingresos, no cambia el flujo de ingresos efectivos del hogar. Sin embargo, puede considerarse que cambia su bienestar, ya que el deseo de trabajar del miembro del hogar (por el motivo que sea), en el ejercicio de su libertad de elegir cómo aplicar los activos de que dispone, se encuentra bloqueado por la falta de oportunidad de hacerlo.

${ }^{41}$ Aún sin considerar la significativa alza del desempleo registrada durante la recesión de 1995/1996 (gráfico 3).
} 
plena recesión, las tasas agregadas de participación y desempleo no diferían mayormente de las imperantes en 1997. Sin embargo, se observan en este período algunos cambios de las tasas de participación de ricos y pobres, cuyo resultado neto es el efecto igualador detectado en el ejercicio de microsimulación.

Estos episodios determinaron la tendencia continuamente ascendente -entre los años con menor componente cíclico- de la desigualdad del ingreso de los hogares, en circunstancias en que la de los perceptores ocupados se mantuvo dentro de órdenes de magnitud bastante comparables entre 1986, 1990/1991 y 1992/1994. El efecto desigualador del aumento del desempleo a fines de los ochenta nunca se revirtió y está, por lo tanto, en la base de la tendencia al deterioro de la distribución de los ingresos familiares. ${ }^{42}$ A ello se agregó el efecto del desempleo de nuevo cuño, cuyo carácter estructural se hizo claramente manifiesto en
1994, cuando la economía alcanzó un máximo aprovechamiento de su capacidad productiva, recientemente ampliada. En cambio, el aumento de la desigualdad en el ingreso de los hogares entre 1994 y 1997 respondió más al incremento de la desigualdad generada en el aparato productivo (gráfico 1), influencia que se continuó manifestando en la ulterior elevación durante la fase recesiva, hasta el año 2000.

En comparación con los ingresos laborales (remuneraciones, participación y desempleo), la evolución de los ingresos no laborales ha influido sólo marginalmente sobre el aumento de la desigualdad de los ingresos de los hogares. Como ya se ha señalado, tanto la evolución de las jubilaciones como la de los ingresos de la propiedad contribuyeron en los años noventa a aumentar la desigualdad, pero en magnitudes poco significativas ${ }^{43}$ en relación con el incremento global (cuadro 8).

\section{VII}

\section{El papel de la política económica y las reformas}

Las políticas económicas gravitan decisivamente sobre la distribución del ingreso. El éxito o fracaso de la regulación macroeconómica incide en el nivel de actividad y el empleo; el régimen macroeconómico, los regímenes sectoriales y la regulación de mercados configuran el sistema de incentivos que orientan la inversión, con sus consecuencias sobre la demanda de trabajo y las remuneraciones; la política fiscal tiene, a su vez, múltiples repercusiones distributivas. Sin embargo, no es válido atribuir a la política económica la entera responsabilidad por la evolución de la distribución del ingreso. En economías mixtas, ésta resulta moldeada por las decisiones autónomas de las empresas y por la conducta de los hogares, dada la distribución de la riqueza, en el ambiente constituido por los incentivos emergentes de los mercados -internos y externosde las instituciones que regulan el orden económico, del régimen macroeconómico y de las disposiciones

\footnotetext{
42 Pueden existir, asimismo, otros factores no considerados en el ejercicio de microsimulación - y que, por lo tanto, se encontrarían operando dentro de la "caja negra" constituida por la porción no explicada del cambio de la desigualdad - que igualmente actúen con cierta histéresis, o bien hayan sufrido cambios permanentes que favorecen la desigualdad entre los hogares, pero no entre los perceptores.
}

que regulan los mercados, en un escenario donde el Estado es, además, un actor económico principal.

Este boceto de la posición "ambiental" de la política económica tiene por propósito despojarla de la imagen de omnipotencia con que se suele analizar tanto su origen como sus consecuencias, con la contrapartida de que se le atribuya la responsabilidad de todo lo que ocurre en la economía. Sirve, además, para recordar la vigorosa presencia de las tendencias de cambio estructural -incluidas las que moldean el sistema político y el aparato gubernativo-, que actúan en buena medida fuera del alcance de la política económica. Hecho eso, volvamos a vestir la imagen de la política pública con la potencia que efectivamente tiene para intervenir y contribuir a alcanzar resultados $-o$ generar perturbaciones-, sobre todo en economías jóvenes, con instituciones de incipiente desarrollo y muchos mercados incompletos.

\footnotetext{
${ }^{43}$ En lo que se refiere a los ingresos de la propiedad, si se consideran sólo los captados por la EPH; éstos constituyen una proporción menor del total de ingresos de los hogares que podrían estimarse si se incluyeran los percibidos en efectivo dentro del país y no declarados a la encuesta o no captados por ésta, las utilidades no distribuidas de empresas locales y los ingresos percibidos como rendimiento de activos colocados por los hogares en el exterior.
} 
Dadas las dificultades para modelar eficazmente el complejo de relaciones que vinculan la política económica y la distribución de la riqueza y del ingreso, intentamos aquilatar la influencia de aquélla sobre éstas observando tanto la asociación temporal entre cambios importantes de la política económica (reformas institucionales, régimen macroeconómico y regulación laboral), con los consiguientes cambios en el sistema de incentivos, como el comportamiento aparente de la demanda de trabajo, asociado a los cambios en el mercado de trabajo que han tenido mayores consecuencias distributivas, según nuestro análisis anterior de microsimulación.

\section{El intento de reforma de los años setenta}

El trienio 1973-1975 estuvo dominado por el intento, finalmente fracasado, del gobierno de Perón de estabilizar la economía sobre la base de un pacto social que congelara precios y salarios, luego de un aumento generalizado de salarios. La política de estabilización se tradujo en el aumento ya señalado de los ingresos reales a lo largo de toda la distribución, pero sin alterar significativamente la distribución relativa del ingreso que había prevalecido hasta principios de la década. En 1975 la economía entró en recesión y a principios de 1976 bordeaba la hiperinflación (Gerchunoff y Llach, 1998).

Entre 1976 y 1980 se desplegaron políticas - la mayoría de corte ortodoxo- cuyo principal objetivo fue la lucha contra la inflación y, complementariamente, la liberalización de la economía. La política de estabilización, basada en el congelamiento de salarios y la devaluación programada del tipo de cambio, en un marco de represión sindical que era funcional asimismo a los requerimientos políticos del régimen militar, desembocó en un derrumbe de los salarios reales. La política laboral, sin embargo, incluyó limitaciones a la desocupación, impuestas por las autoridades militares a las económicas y por éstas —informalmente- a las empresas (Canitrot, 1981), en procura de minimizar el conflicto social fuera del ámbito de la represión, con lo que el desempleo en 1980 fue de apenas $2 \%$.

Las reformas de los años setenta incluyeron una considerable apertura comercial ${ }^{44}$ y de la cuenta de capitales del balance de pagos, así como la desregulación del mercado financiero interno (gráfico 7). Estas refor-

\footnotetext{
44 Aunque relativamente moderada (en vista de lo redundante de los aranceles vigentes) y gradual: consistió en reducciones arancelarias cercanas al 50\%, con tratamiento diferenciado para las industrias básicas, a completarse en 1984 (Canitrot, 1993).
}

mas se consideraron componentes esenciales del programa de estabilización, basado en el enfoque monetario del balance de pagos. Una de sus consecuencias fue una elevada apreciación cambiaria que, combinada con la desgravación arancelaria, disminuyó considerablemente la protección a la actividad interna. Otra, una expansión de la actividad económica basada en el endeudamiento externo (Canitrot, 1993), junto con una hipertrofia de la actividad financiera. La reducción a cerca de la mitad de los aranceles para los bienes de capital, sumada a la apreciación de la moneda en $20 \%$, abarataron la inversión, aunque los elevados niveles reales ( $25 \%$ en promedio) de las tasas de interés activas operaron en sentido contrario. Por otro lado, las empresas se vieron beneficiadas por la modificación a su favor de las relaciones sindicales y por la supresión del aporte patronal al sistema de jubilación, por lo menos hasta que se vieron afectadas por la aceleración inflacionaria y la reducción del mercado por la competencia de sustitutos importados.

La inversión realizada en estas condiciones implicó un proceso de transformación productiva. En la industria - que contrajo su volumen de producción en $20 \%$, bajando casi cuatro puntos su participación en el producto- perdieron terreno las ramas metalmecánicas y eléctricas, en beneficio de commodities industriales basadas en recursos naturales y de las industrias regionales de sectores tradicionales, amparadas en ambos casos por franquicias fiscales. En general, tendió a aumentar la integración vertical, como medio de retener al personal calificado y así evitar los costos de reentrenamiento ${ }^{45}$ (Katz y Kosacoff, 1989).

En esas circunstancias, no resulta extraño que se haya acentuado la desigualdad de las remuneraciones, con ampliación de los "premios" por educación. Las empresas habrían aplicado la estrategia de resguardar de la inflación a su personal más calificado, para retenerlo e incentivarlo, mientras el personal menos calificado — sin mayor defensa sindical— se rezagaba, aunque sin caer en el desempleo. Por otra parte, en este período aumentaron significativamente los trabajadores por cuenta propia quienes, con una relativa capacidad de fijar precios en un contexto de alta inflación y desprotección salarial, pudieron defender mejor sus ingresos reales ${ }^{46}$ (cuadro 9).

\footnotetext{
45 Esta actitud revelaba la creencia de que el futuro iba a ser de reactivación, más que de transformación.

46 Aunque el segmento más informal de estos contingentes haya cambiado de categoría como una alternativa al desempleo, éste parece ser un caso minoritario, dada la situación del mercado de trabajo.
} 
Gran Buenos Aires: Evolución del ingreso medio real de la ocupación principal, por niveles de educación

(Ocupados con una sola ocupación, 35 horas y más. Variaciones porcentuales entre extremos del período)

\begin{tabular}{|c|c|c|c|c|c|c|}
\hline & $1974-1980$ & $1980-1986$ & $1986-1990$ & 1990-1994 & 1994-1997 & $1997-2000$ \\
\hline \multicolumn{7}{|l|}{ Ocupados totales } \\
\hline Primaria incompleta ${ }^{a}$ & -19.4 & -14.2 & -31.0 & 25.4 & -16.7 & 0.5 \\
\hline Primaria completa & -18.5 & -13.0 & -36.8 & 24.4 & -12.5 & -3.5 \\
\hline Secundaria incompleta & -21.3 & -7.0 & -35.9 & 21.9 & -19.0 & -3.2 \\
\hline Secundaria completa & -9.4 & -14.0 & -41.3 & 32.4 & -10.5 & -1.4 \\
\hline Universitaria incompleta & 4.5 & -18.4 & -30.1 & 29.6 & -23.8 & 0.7 \\
\hline Universitaria completa & 9.5 & -14.9 & -30.7 & 10.3 & -1.4 & 3.3 \\
\hline \multicolumn{7}{|l|}{ Asalariados } \\
\hline Primaria incompleta ${ }^{a}$ & -27.7 & -9.4 & -33.9 & 27.7 & -5.5 & -7.5 \\
\hline Primaria completa & -25.4 & -8.8 & -35.4 & 24.2 & -12.9 & -0.7 \\
\hline Secundaria incompleta & -25.6 & -7.4 & -28.9 & 14.0 & -20.1 & -0.9 \\
\hline Secundaria completa & -16.8 & -17.4 & -36.7 & 22.1 & -4.4 & -1.9 \\
\hline Universitaria incompleta & 4.8 & -21.1 & -30.3 & 21.9 & -18.5 & 0.0 \\
\hline Universitaria completa & 2.6 & -24.8 & -23.3 & 15.6 & -8.0 & 9.6 \\
\hline \multicolumn{7}{|l|}{ No asalariados } \\
\hline Primaria incompleta ${ }^{a}$ & -1.2 & -19.3 & -44.1 & -5.2 & -35.6 & 164.0 \\
\hline Primaria completa & -15.2 & -4.2 & -47.9 & 20.6 & -8.1 & 102.4 \\
\hline Secundaria incompleta & 20.3 & -9.8 & -48.6 & 34.7 & -12.5 & 100.9 \\
\hline Secundaria completa & 2.7 & -5.1 & -25.0 & 52.8 & -17.8 & 42.9 \\
\hline Universitaria incompleta & 22.8 & 1.1 & -39.7 & 42.8 & -34.7 & 46.7 \\
\hline Universitaria completa & -13.2 & $\ldots$ & $\ldots$ & 5.1 & 10.7 & 14.9 \\
\hline
\end{tabular}

Fuente: Elaboración propia, basada en datos de la EPH.

a Incluye personas sin estudios formales.

\section{La década de crisis}

La política económica sufrió numerosas vicisitudes en esta década, respondiendo a la volatilidad macroeconómica pero también contribuyendo a ella. En 1981 se abandonó el enfoque monetario de la balanza de pagos. En 1982, la reversión del financiamiento externo, la caída de los precios de las exportaciones y las elevadas tasas de interés internacionales configuraron una situación crítica, que obligó al cierre de las importaciones y a una moratoria de hecho de la deuda externa. La derrota en la guerra de las Malvinas selló la suerte del régimen militar. El gobierno constitucional que asumió en 1983 intentó inicialmente continuar con la política salarial expansiva iniciada durante la retirada militar y negociar una salida política al sobreendeudamiento. Hacia 1984, se habían revertido la apertura comercial, la de la cuenta de capital y la reforma financiera (gráfico 7). En 1985, la administración Alfonsín logró conciliar el acuerdo vigente con el Fondo Monetario Internacional (FMI) y la renegociación de la deuda externa, con la adopción de un pro- grama heterodoxo de estabilización, que congeló los precios a niveles relativos previamente acomodados y previó la reducción del déficit fiscal; para esto último se estableció la regla de no financiarlo con emisión. Hacia el tercer trimestre de 1986 el PIB había recuperado el nivel de 1980, pero el ritmo inflacionario ya se había reacelerado. Si bien el empleo había alcanzado una nueva cima, la tasa de desocupación seguía aumentando tendencialmente y los salarios reales estaban descendiendo (cuadro 1).

En 1987, una sucesión de problemas políticos, la ulterior caída de los precios externos y la aceleración inflacionaria obligaron a un nuevo programa de estabilización, con apoyo externo condicionado a reformas (entre ellas una rebaja de aranceles). La inminencia del triunfo electoral del peronismo, con un programa populista y de moratoria unilateral, provocó una corrida cambiaria a principios de 1989, que desencadenó la hiperinflación y acentuó la recesión que se manifestaba desde hacía más de un año.

Si bien los anuncios de liberalización, privatizaciones y austeridad fiscal del nuevo gobierno aquieta- 


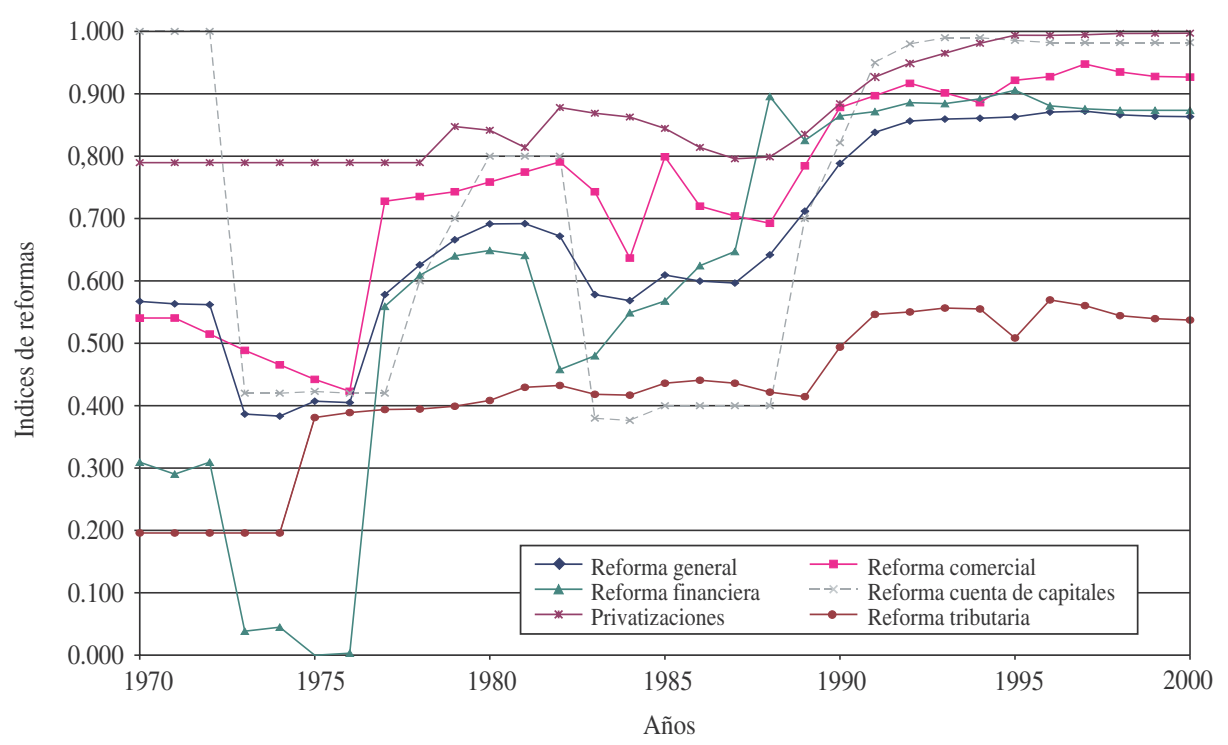

Fuente: CEPAL. División de Desarrollo Económico.

ron la incertidumbre y el ritmo de la inflación, la progresiva apreciación cambiaria y la recurrencia al crédito interno para financiar el déficit fiscal condujeron a un segundo estallido hiperinflacionario, a principios de 1990. Este fue superado con una estrategia monetarista, una tregua con los acreedores externos y una política fiscal "de caja". El abandono de esta última y el uso renovado del crédito interno por parte del fisco provocaron un retorno de la amenaza de hiperinflación.

En este conflictivo período, la economía adoleció de falta de una política económica consistente, a la vez que de un exceso de políticas que resultaron pasajeras $y$, por ende, de fracasos, productores de más inestabilidad. Como resultado, el sistema de incentivos sufrió fuertes oscilaciones y la inversión se debilitó y desorientó, fragmentándose el anterior proceso de transformación productiva. Por otra parte, hasta 1988 no se retomó el sendero de apertura y de desregulación (gráfico 7).

En la primera parte del decenio, la debilidad productiva comenzó a manifestarse en la ampliación del desempleo y el aumento del empleo informal. Por otro lado, la estabilización de 1986 permitió la mejora parcial de las remuneraciones reales y —en el nuevo contexto de libertad sindical - se recuperaron relativamente más las de los asalariados de menores calificaciones, con lo que se atenuaron las diferencias de remu- neración por niveles educativos y retrocedieron en términos relativos las remuneraciones de los trabajadores por cuenta propia. El posterior estallido inflacionario dominó la escena, pero el deterioro de las remuneraciones reales afectó de forma relativamente pareja a todos los niveles de calificación (cuadro 9). En definitiva, al culminar la década de crisis, los "premios" por educación y la dispersión de las remuneraciones horarias no eran sustancialmente distintos que en sus inicios, como resultado de una demanda de trabajo vacilante y sin sesgos significativos.

\section{Las reformas de los noventa y la converti- bilidad}

a) La política y la evolución macroeconómica

A principios de 1991 se adoptó una estrategia de reformas liberales y rápida desinflación, para lo cual se estableció la convertibilidad de la moneda nacional y se impusieron reglas estrictas para evitar el financiamiento monetario del déficit fiscal; se anunciaron reformas tributarias y la acelerada privatización de empresas públicas; se liberaron completamente los movimientos de capitales, y se procedió a una considerable liberalización del comercio exterior, acelerando drásticamente un proceso que se venía desplegando con lentitud desde fines de la década anterior (gráfico 7). 
Asimismo, se eliminaron los impuestos a las exportaciones y las restricciones cuantitativas a las importaciones y se redujeron significativamente los aranceles, con el propósito de establecer un sistema de incentivos neutrales entre exportaciones e importaciones.

La desinflación fue rápida; en pocos meses la tasa de inflación se ubicó en torno a $1 \%$ mensual. La recuperación del salario real y el incremento del crédito al consumo indujeron una ampliación de la demanda. Por otro lado, la recaudación tributaria se duplicó en términos reales y el déficit fiscal tendió a desaparecer. La estabilidad macroeconómica y las reformas estructurales infundieron confianza a los inversores y se conjugaron con factores externos para impulsar una afluencia masiva de capitales privados voluntarios, en el marco del nuevo y liberal régimen de movimiento de capitales.

El efecto combinado de la brusca liberalización comercial y la fijación del tipo de cambio hizo que los precios industriales se comportaran como los de bienes plenamente transables, rezagándose con respecto a los precios de los no transables. Esta evolución de los precios relativos, en un contexto de tipo de cambio fijo, representó una considerable apreciación de la moneda entre 1991 y 1994. Por otra parte, las tasas de interés cayeron drásticamente, volviéndose negativas por varios meses las tasas pasivas en términos reales.

Hacia 1994 la afluencia de capitales se desaceleró, en tanto que el déficit en cuenta corriente continuaba ampliándose. Algunos sectores productivos mostraban incipientes síntomas recesivos. Pero la posible contracción gradual que se insinuaba quedó brutalmente superada por los efectos de la crisis mexicana; éstos se tradujeron en una abrupta contracción del crédito, junto con un deterioro de las expectativas, que indujeron una aguda reducción de la demanda interna. Se evitó el colapso del programa con medidas monetarias y, hacia el tercer trimestre de 1996, el PIB ya había recuperado el nivel que registrara en igual período de 1994. El aumento de la demanda agregada se tradujo en una significativa expansión de las importaciones. Sin embargo, dado el incremento del valor de las exportaciones, el balance comercial terminó equilibrado y la renovada entrada de capitales financió sin perturbaciones el déficit en cuenta corriente. En 1997, el crecimiento se tornó vigoroso (8\%), en medio de una absoluta estabilidad de precios.

El deterioro paralelo de la cuenta corriente del balance de pagos y de las cuentas fiscales tornaron la sostenibilidad macroeconómica aún más dependiente del ingreso de capitales. En estas condiciones, la re- ducción de las corrientes de capitales como consecuencia de la crisis rusa provocó una contracción del crédito que marcó en 1998 el comienzo de la recesión del nivel de actividad, la que se fue prolongando y agravó la dependencia de unos capitales externos cada vez más esquivos. En 1999, la administración Menem relajó la política fiscal, en pos de un proyecto continuista. Frente al aumento del déficit fiscal y en procura de afianzar la credibilidad de su política frente a los inversores, el nuevo gobierno recurrió a medidas fiscales contractivas a principios del año 2000. Pero la erosión de la confianza continuó, acelerada por la percepción de conflictos políticos crecientes, en un proceso que culminaría a fines de 2001 con el colapso del sistema bancario y el abandono del régimen de convertibilidad.

\section{b) Influencia sobre el desempeño laboral y distribu- tivo}

La evolución y características de la demanda de trabajo durante el decenio de 1990, en el marco de incentivos establecidos por el nuevo orden económico y el régimen de convertibilidad, ejercieron sus influencias distributivas tanto mediante el nivel del empleo de tiempo completo, del subempleo y del consiguiente desempleo, como a través de la intensidad de la demanda de fuerza de trabajo con diferentes calificaciones.

Más allá del comportamiento cíclico, ${ }^{47}$ las dos fases expansivas de la década, que culminaron respectivamente en 1994 y 1997/1998, representaron dos etapas diferentes del comportamiento de la demanda agregada de trabajo. En la primera, la recuperación y posterior expansión del PIB (a un ritmo anual de 8.7\%) se basó casi enteramente en aumentos de productividad, en tanto que el empleo total se amplió lentamente (a razón de $0.8 \%$ anual) y el industrial se contrajo (cuadro 10). Como ya se mencionó, el considerable aumento de la productividad debe interpretarse como debido en parte a la reactivación en el nuevo marco de estabilidad y afluencia de capitales, y en parte a un desplazamiento de la frontera de producción con cambio técnico. Este desplazamiento, a su vez, habría derivado de inversiones facilitadas por la apertura, la apreciación cambiaria y el financiamiento externo, así como de la reorganización de los procesos de trabajo con poca inversión, ambas estrategias motivadas por la búsqueda de mayor competitividad internacional en el nuevo contexto (Altimir y Beccaria, 2000b).

\footnotetext{
${ }^{47}$ Que es considerado, entre otros, por Damill, Frenkel y Maurizio (2002).
} 
Argentina: Evolución del producto, el empleo y la productividad en los años noventa (Tasa media de variación anual entre extremos)

\begin{tabular}{|c|c|c|c|c|c|c|c|c|c|c|c|c|}
\hline & \multicolumn{4}{|c|}{ Producto interno bruto } & \multicolumn{4}{|c|}{ Empleo total } & \multicolumn{4}{|c|}{ Productividad } \\
\hline & 1991(I) & 1994(IV) & 1995(III) & 1991(I) & 1991(I) & 1994(IV) & 1995(III) & 1991(I) & 1991(I) & 1994(IV) & 1995(III) & 1991(I) \\
\hline & 1994(IV) & 1995(III) & 1997(IV) & 1997(IV) & 1994(IV) & 1995(III) & 1997(IV) & 1997(IV) & 1994(IV) & 1995(III) & 1997(IV) & 1997(IV) \\
\hline Total $^{\mathrm{a}}$ & 8.7 & -10.3 & 8.0 & 6.2 & 0.8 & -2.2 & 3.9 & 1.5 & 7.9 & -8.3 & 4.0 & 4.7 \\
\hline Subtotal Industrias & 8.9 & -13.2 & 8.8 & 6.1 & -2.3 & -6.3 & 1.3 & -1.6 & 11.5 & -7.3 & 7.4 & 7.9 \\
\hline Alimentos, bebidas y tabacos & 5.1 & 8.2 & 1.7 & 4.3 & 0.0 & 8.8 & -2.2 & 0.2 & 5.1 & -0.6 & 4.0 & 4.1 \\
\hline Textiles y confecciones & 1.4 & -19.5 & 5.3 & 0.0 & -12.0 & 0.3 & 2.5 & -6.1 & 15.2 & -19.7 & 2.7 & 6.5 \\
\hline Madera, muebles y otras industrias & 9.7 & -29.4 & 26.8 & 9.6 & 3.3 & -30.6 & 5.2 & -0.6 & 6.2 & 1.7 & 20.5 & 10.2 \\
\hline Papel e imprentas & 13.0 & -11.9 & 6.7 & 7.8 & 7.7 & -10.5 & -4.8 & 1.3 & 4.9 & -1.5 & 12.0 & 6.5 \\
\hline Petróleo y químicas & 9.5 & -13.1 & 6.5 & 5.7 & -2.5 & 4.1 & 3.6 & 0.2 & 12.3 & -16.4 & 2.8 & 5.5 \\
\hline Productos minerales no metálicos & 11.5 & -20.7 & 11.0 & 7.2 & 0.2 & 22.3 & -6.5 & 0.1 & 11.2 & -35.1 & 18.6 & 7.0 \\
\hline Metalmecánicas & 14.3 & -24.6 & 17.2 & 10.0 & -0.7 & -15.7 & 3.7 & -1.0 & 15.1 & -10.6 & 13.0 & 11.2 \\
\hline Construcción & 17.0 & -24.9 & 16.1 & 11.1 & 3.4 & -11.5 & 7.9 & 3.1 & 13.1 & -15.1 & 7.6 & 7.8 \\
\hline Comercio & 8.7 & -15.2 & 11.0 & 6.5 & -0.5 & -9.3 & 2.4 & -0.6 & 9.3 & -6.5 & 8.4 & 7.1 \\
\hline Hoteles y restaurantes & 10.2 & -12.3 & 10.6 & 7.6 & 6.2 & 11.4 & -3.6 & 3.4 & 3.8 & -21.2 & 14.7 & 4.1 \\
\hline Auxiliares de transporte & 2.8 & -12.8 & 7.7 & 2.5 & 35.0 & 18.7 & -2.4 & 19.5 & -23.9 & -26.5 & 10.3 & -14.2 \\
\hline Bancos y seguros & 17.4 & -9.2 & 14.2 & 13.1 & 3.4 & 0.1 & 5.4 & 3.7 & 13.5 & -9.3 & 8.3 & 9.0 \\
\hline Servicios públicos privatizados & 10.7 & 6.8 & 8.3 & 9.4 & 0.9 & 19.8 & 0.7 & 2.8 & 9.7 & -10.9 & 7.5 & 6.5 \\
\hline Servicios profesionales y a empresas & 13.5 & -1.7 & 4.8 & 8.8 & 3.2 & 18.4 & 5.5 & 5.6 & 10.0 & -17.0 & -0.6 & 3.1 \\
\hline Educación y salud privadas & 2.1 & 0.2 & 0.3 & 1.3 & 2.0 & -0.5 & 6.1 & 3.1 & 0.1 & 0.7 & -5.5 & -1.7 \\
\hline Gobierno & 5.3 & -2.0 & -4.9 & 1.0 & 1.7 & 3.0 & 3.9 & 2.6 & 3.5 & -4.9 & -8.5 & -1.6 \\
\hline Otros servicios & 5.8 & -7.5 & 5.6 & 4.2 & -2.9 & 1.8 & 5.8 & 0.4 & 8.9 & -9.1 & -0.2 & 3.7 \\
\hline Servicio doméstico & 2.5 & -7.2 & 4.7 & 2.1 & 2.3 & -1.0 & 3.7 & 2.4 & 0.2 & 6.3 & 1.0 & -0.3 \\
\hline
\end{tabular}

Fuente: Elaboración propia, basada en datos de la EPH.

a Excluye actividades primarias.

En la segunda fase expansiva ${ }^{48}$ en cambio, el crecimiento del PIB (a una tasa de 8\% anual, cercana a la de la fase anterior) se apoyó en proporciones similares en la ampliación del empleo y en aumentos de productividad, aunque en la industria fueron estos últimos los que continuaron liderando el proceso y constriñendo la creación de empleos (cuadro 10).

El ya mencionado estudio de Damill, Frenkel y Maurizio (2002) concuerda con estas apreciaciones en la medida en que sus resultados econométricos sugieren que el período de ajuste contractivo del empleo de tiempo completo al nuevo entorno se habría completado en 1996. Sin embargo, en el caso de las manufacturas dicho ajuste habría continuado más allá de 1996.

El establecimiento y despliegue del nuevo orden económico y del régimen macroeconómico incidieron

\footnotetext{
${ }^{48}$ Considerando la fase ascendente del ciclo, desde el comienzo de la recuperación posterior al episodio del tequila en el tercer trimestre de 1995 hasta el cuarto trimestre de 1997 (aunque esta fase se prolongó hasta mediados de 1998, cuando comenzó a desarrollarse la recesión).
}

sobre la evolución de la demanda de trabajo, principalmente a través de la inversión. Esta registró un auge en los años noventa —apoyada en las corrientes de capital externo- en respuesta a la estabilización, las nuevas reglas, la expansión de la demanda agregada y el cambio de los precios relativos a favor de la acumulación de capital (Ramos y Martínez, 2000). La reducción de los aranceles y la apreciación cambiaria — fruto del régimen macroeconómico- cambiaron radicalmente los precios relativos del trabajo y el capital: mientras los salarios industriales se duplicaron en dólares, los bienes de capital se abarataron considerablemente. ${ }^{49}$ Esto promovió una actualización tecnológica que había sido postergada por la debilidad inversora de los ochenta, e incentivó la sustitución de trabajo por capital en toda la economía a través de un uso más intensivo de capital en la producción, con

\footnotetext{
${ }^{49}$ En una medida que minimizó el efecto del alza en las tasas de interés reales, que con la estabilidad de precios pasaron a ser positivas.
} 
la consiguiente merma de la elasticidad empleoproducto. ${ }^{50}$ Por otro lado, la apertura a las importaciones, unida a la apreciación cambiaria, obligaba a la búsqueda de competitividad internacional en el mercado interno, sobre la base de mejoras sustanciales de la productividad ${ }^{51} \mathrm{y}$ del ahorro de mano de obra.

Pero también hubo destrucción de puestos de trabajo, asociada con la implantación del nuevo orden. La apertura comercial indujo desinversión — con la consiguiente pérdida de puestos-al provocar el cierre de empresas o plantas, principalmente industriales y pequeñas o medianas. Por otro lado, parte de los aumentos de productividad se obtuvieron mediante reducciones de personal por racionalización de los procesos de trabajo, sin mayores inversiones en capital fijo. También hubo despidos en las empresas privatizadas, aunque éstos sólo explican una pequeña parte de la expansión registrada en el desempleo total. ${ }^{52}$

Las inversiones en nueva tecnología también deben haber sesgado la demanda de trabajo en favor de las calificaciones más altas, en la medida en que éstas sean complementarias del nuevo capital (o de los esquemas organizacionales) con tecnología más reciente. Ese sesgo se observa, a nivel agregado, no sólo en el empleo, sino también en las remuneraciones, aunque con mayor intensidad en la segunda fase expansiva que en la primera.

Estos efectos indirectos - no todos intencionales- de la política económica sobre la situación laboral y distributiva no constituyen sino una parte de la historia. Otra parte importante del papel desempeñado en ese plano por la política económica es la medida

\section{VIII}

\section{Conclusiones}

La tendencia al aumento persistente y en buena medida estructural de la desigualdad en los ingresos fami-

\footnotetext{
${ }^{50}$ La elasticidad empleo-producto entre el primer trimestre de 1990 y el cuarto de 1994 fue de 0.16, en comparación con 0.37 entre mediados de 1985 y el tercer trimestre de 1987. En cambio, en la segunda fase expansiva, entre el primer trimestre de 1995 y el cuarto de 1997, la elasticidad fue de 0.48 (Altimir y Beccaria, 2000b). ${ }^{51}$ Las exportaciones, en cambio, aunque también favorecidas en sus inversiones por el precio del capital, enfrentaron el desincentivo representado por la apreciación de la moneda.

52 Un cálculo tentativo ubica la caída del empleo en empresas públicas en torno a 150000 puestos de trabajo entre 1991 y 1995 ,
}

en que ha sido capaz de sostener el nivel de actividad $\mathrm{y}$, por lo tanto, el de la demanda de empleo y la productividad. El esquema de reformas al orden económico y régimen macroeconómico de convertibilidad fue altamente exitoso en la estabilización, la reanimación de la inversión y la recuperación y expansión de la economía, hasta la crisis del tequila. Sortear ésta con ayuda internacional y con eficacia permitió renovar la confianza en un régimen macroeconómico cuya inflexibilidad, que había sido su virtud original, se estaba revelando como su debilidad.

La paridad fija, además de conspirar con la apreciación de la moneda contra la competitividad de las exportaciones, despojaba a la política de coyuntura de un instrumento clave y - junto con la dolarización del crédito- convertía a la política cambiaria en eje de referencia de los contratos y exponía plenamente el crédito interno y el nivel de actividad a los shocks externos (Heymann, 2000). El equilibrio fiscal, por su lado, sufría crecientes tensiones entre la necesidad de sustituir la política cambiaria por rebajas de tributos que contribuyeran a elevar la competitividad, proporcionar estímulos al empleo y atender crecientes demandas sociales y políticas. El ascendente endeudamiento público externo para cerrar la ecuación fiscal configuró el preludio de la situación que finalmente desembocaría en el colapso de fines de 2001. Poca duda cabe de que el mantenimiento a ultranza de un régimen peligrosamente vulnerable y que con el tiempo se haría insostenible tiene buena parte de la responsabilidad por la crisis social que se desató después de su derrumbe, y cuyo análisis supera los límites de este artículo.

liares está principalmente determinada por fuerzas que actúan en el mercado de trabajo, las que se reflejan en la estructura de las remuneraciones, en la evolución de la oferta de trabajo y en el desajuste entre oferta y demanda, dando lugar, entre otras cosas, a la ampliación del desempleo. Sin embargo, resulta de distintas combinaciones de factores, según las épocas.

cifra que constituye un $10 \%$ del aumento de la desocupación registrada sólo en las ciudades cubiertas por la EPH (Altimir y Beccaria, 2000b). 
Como imagen estilizada, el deterioro de la distribución del bienestar en el último cuarto de siglo se produjo en cuatro fases: i) en los años setenta, a través de la reducción real de las remuneraciones y su dispersión relativa, en el contexto de un ajuste ortodoxo (pero con restricción al desempleo) y un proceso de apertura; ii) en los ochenta, a través del impacto del creciente desempleo debido a sucesivas crisis, con escasa reestructuración y una cierta resiliencia de la estructura de remuneraciones; iii) en la primera fase de expansión de los noventa, bajo un nuevo orden económico, abierto al exterior, con el activismo estatal en retroceso y con estabilidad de precios, a través del creciente desempleo generado por una demanda de trabajo inelástica - como consecuencia de la reestructuración productiva - y una oferta de trabajo ampliada por mayores deseos de participación; y iv) en la última fase expansiva, a través de una mayor desigualdad de las remuneraciones.

La desigualdad de las remuneraciones también tendió a aumentar —en menor medida que la de los ingresos familiares - entre 1974 y 2000, pero como resultado de dos olas de empeoramiento: la ocurrida en la segunda mitad de los años setenta y la que tuvo lugar en los noventa. En ambas instancias, ese incremento fue determinante del registrado por la concentración del ingreso de los hogares.

Los dos procesos de apertura - el ensayo de los años setenta y la reforma de los noventa- habrían traído consigo reestructuraciones del empleo con consecuencias distributivas negativas. En los setenta, la fuerte caída de los salarios reales, que también contribuyó a la competitividad, hizo viable la considerable ampliación de las diferencias salariales vinculadas a la calificación y, por otro lado, el mantenimiento del nivel de empleo acotó la reestructuración productiva. El nuevo orden económico de los noventa, en cambio, usó la apertura como instrumento de reestructuración profunda, admitiendo la ampliación sin precedentes del desempleo en tiempos de expansión. En una primera fase, la reestructuración — sobre todo en la industriase centró en la racionalización del empleo y el ahorro de mano de obra, con la consiguiente elevación del desempleo, en tanto que el sesgo derivado de la demanda de calificación tuvo una importancia relativamente menor. En la segunda fase, los papeles se invirtieron: el sesgo en favor de mayor calificación en la demanda de fuerza de trabajo se tradujo en un incremento de las diferencias salariales, en tanto que el nivel de empleo se mantuvo y su elasticidad se elevó, con aumentos menos intensos de productividad. Quizá ello sea reflejo de que la reestructuración había permitido recuperarse, en un corto lapso, de lo esencial del atraso tecnológico, al menos en una perspectiva empresarial de mediano plazo.

En definitiva, la historia estilizada del deterioro distributivo que hemos presentado puede interpretarse como una dimensión del largo y azaroso proceso de transformación del estilo de desarrollo de posguerra —de industrialización sustitutiva y liderado por el Estado- en un estilo más funcional a la integración en la economía internacional y en los procesos de globalización, con predominio de las fuerzas de mercado.

En esa perspectiva, ambas instancias de reforma del orden económico constituyeron estrategias de estabilización, desregulación y apertura, con propósitos de transformación del estilo de desarrollo. Sin embargo, los aspectos concretos de la política antiinflacionaria tuvieron una incidencia decisiva sobre el proceso de transformación productiva. El congelamiento de salarios en los setenta favoreció tanto la competitividad como la ampliación de las diferencias salariales. El tipo de cambio fijo, en los noventa, hizo más drástica la apertura a las importaciones, abarató artificialmente los bienes de capital, elevó los costos salariales en dólares y desfavoreció las exportaciones, particularmente las que hacen uso intensivo de trabajo; todos incentivos contrarios al empleo. En el proceso de los noventa, el ahorro de mano de obra en general parece haber tenido precedencia sobre la demanda de fuerza de trabajo más calificada, demanda que sin embargo terminó por acrecentar las diferencias de salarios.

No obstante, puede pensarse que, por debajo de estas distorsiones que exageraron los efectos negativos tanto del primer intento de liberalización como de la reforma reciente del orden económico, la mayor libertad económica posibilitó el despliegue de fuerzas de mercado que orientaron las inversiones hacia un patrón productivo más integrado a la economía internacional. Ese proceso de transformación, sin embargo, fue guiado solamente por las señales de mercado, dado que el diseño de las reformas no incluyó mecanismos de política industrial o tecnológica que contribuyeran al desarrollo de ventajas comparativas dinámicas.

El nuevo estilo de funcionamiento de la economía determina, más allá de la apreciación cambiaria y del ulterior colapso del régimen macroeconómico que acompañó a las reformas institucionales y desembocó en la crisis actual, una menor elasticidad del empleo 
respecto al crecimiento, con el consiguiente desempleo estructural, y mayores diferencias salariales por niveles de calificación. Sin embargo, con esa determinación de trasfondo, hay espacio en el escenario para que la política pública intente, por un lado, guiar a las fuerzas productivas hacia una integración más dinámica en la economía internacional que involucre la creación de empleos de calidad y la elevación de todas las remuneraciones, y desarrolle, por el otro, sistemas de protección social eficaces para atender las múltiples situaciones de vulnerabilidad que el nuevo estilo de funcionamiento trae consigo.

APÉNDICE

\section{Modelo y metodología de microsimulaciones}

La metodología está basada en la estimación de un modelo de participación policotómico o discreto de participación individual en la fuerza de trabajo. En ese modelo, cada individuo en edad activa puede hallarse en una de tres alternativas recíprocamente excluyentes: 1) empleado, 2) desempleado o 3) fuera de la fuerza de trabajo. Se supone, sin pérdida de generalidad, que hay $N_{1}$ individuos empleados, $N_{2}$ individuos desempleados y $N_{3}$ individuos que están fuera de la fuerza de trabajo, de forma tal que $N=N_{1}+N_{2}+$ $N_{3}$.

Supóngase que $V_{i j}$ es la utilidad máxima alcanzada por el individuo $i$ si elige la alternativa $j$. Si $V_{i j}$ es lineal,

$$
V_{i j}=\delta_{j}^{\prime} x_{i}+u_{i j}, \quad i=1,2, \ldots, N
$$

donde $x_{i}$ es un vector de características del individuo que captan toda la información relevante para seleccionar la alternativa para la que $V_{i j}$ es máxima, y $u_{i j}$ es un término de error que se asume independiente e idénticamente distribuido con una distribución doble exponencial o Gumbel.

Para cada una de las tres alternativas hay una función de utilidad como la [1] y la alternativa $s(s=1,2,3)$ se elige sólo si brinda la mayor utilidad, es decir,

$$
V_{s}>\max _{j \neq s} V_{j}
$$

definiendo

$$
\pi_{s}=\max _{j \neq s} V_{j}-u_{s}
$$

La alternativa $s$ será elegida sólo si $\delta_{s} x_{s}>\pi_{s}$. Como $u_{i j}$ se distribuye independiente e idénticamente con distribución Gumbel y si $X$ es un vector de variables exógenas $\left(X=\left[x_{1}^{\prime}, x_{2}{ }^{\prime}, \ldots, x_{N}^{\prime}\right]^{\prime}\right)$ la distribución $\mathrm{F}\left(\pi_{s}\right)$ de $\pi_{s}$ es

$$
F\left(\pi_{s}\right)=\exp \left(\pi_{s}\right) /\left[\exp \left(\pi_{s}\right)+\sum_{j \neq s}^{3} \exp \left(\delta_{j}{ }^{\prime} X\right)\right],
$$

y la probabilidad de que la alternativa $s$ sea elegida es:

$$
P_{s}=\frac{\exp \left(\delta_{s}{ }^{\prime} X\right)}{\sum_{j=1}^{3} \exp \left(\delta_{j}{ }^{\prime} X\right)},
$$

que es el modelo Logit condicional (véase McFadden, 1974) que se estima mediante el método de máxima verosimilitud. ${ }^{1}$

Las microsimulaciones también requieren asignarles ingresos laborales a aquellas personas en edad activa que no lo tienen porque se encuentran desempleadas o inactivas, para el caso de que resulten seleccionadas para cambiar de situa-

${ }^{1}$ Cabe señalar que las probabilidades para cada una de las tres alternativas son:

$$
\begin{gathered}
P(s=1)=\frac{e^{X} \boldsymbol{\delta}_{1}}{e^{X} \boldsymbol{\delta}_{1}+e^{X} \boldsymbol{\delta}_{2}+e^{X} \boldsymbol{\delta}_{3}} \quad P(s=2)=\frac{e^{X} \boldsymbol{\delta}_{2}}{e^{X} \boldsymbol{\delta}_{1}+e^{X} \boldsymbol{\delta}_{2}+e^{X} \boldsymbol{\delta}_{3}} \\
P(s=3)=\frac{e^{X} \boldsymbol{\delta}_{3}}{e^{X} \boldsymbol{\delta}_{1}+e^{X} \boldsymbol{\delta}_{2}+e^{X} \boldsymbol{\delta}_{3}}
\end{gathered}
$$

Este modelo sin embargo no está identificado en el sentido de que hay más de una solución para $\delta_{1}, \delta_{2}$, y $\delta_{3}$ que lleva a las mismas probabilidades para $s=1, s=2$ e $s=3$. Para identificar el modelo se procedió, como es usual, a elegir una de las tres alternativas como categoría base. Esto es, hacer cero el coeficiente de esa categoría (en este ejercicio, la de los individuos que no participan de la fuerza de trabajo). Multiplicando y dividiendo esas probabilidades por $\mathrm{e}^{-\mathrm{X} \delta 3}$ quedan:

$$
\begin{gathered}
P(s=1)=\frac{e^{X\left(\delta_{1}-\delta_{3}\right)}}{e^{X\left(\delta_{1}-\delta_{3}\right)}+e^{X\left(\delta_{2}-\delta_{3}\right)}+1} \quad P(s=2)=\frac{e^{X\left(\delta_{2}-\delta_{3}\right)}}{e^{X\left(\delta_{1}-\delta_{3}\right)}+e^{X\left(\delta_{2}-\delta_{3}\right)}+1} \\
P(s=3)=\frac{1}{e^{X\left(\delta_{1}-\delta_{3}\right)}+e^{X\left(\delta_{2}-\delta_{3}\right)}+1}
\end{gathered}
$$

Es decir, que los coeficientes estimados se pueden interpretar como el efecto de la diferencia entre el verdadero coeficiente de la categoría y el coeficiente de aquélla elegida como base, sobre la probabilidad. Así, por ejemplo, la probabilidad relativa de los trabajadores empleados comparados con los que no participan de la fuerza de trabajo es:

$$
\frac{P(s=1)}{P(s=3)}=e^{X\left(\delta_{1}-\delta_{3}\right)}=e^{X \beta}
$$

y la estimación de $\beta$ representa el impacto sobre la probabilidad relativa. 
ción de actividad. También para estimar los efectos de cambios en las retribuciones a los atributos sociodemográficos (véase más abajo).

Si el individuo está empleado, su ingreso laboral (en logaritmos) está dado por:

$$
W_{1 i}=\beta_{1}^{\prime} Z_{1 i}+\varepsilon_{1 i}, \quad i=1,2, \ldots, N_{1}
$$

donde el subíndice $i$ se refiere al $i$ ésimo individuo, $Z_{1 i}$ es un vector de características exógenas y $\varepsilon_{1 i}$ es un término aleatorio.

En la ecuación [4] existe sesgo de selección muestral si $\operatorname{los}$ errores $\varepsilon_{\mathrm{i}}$ y $\operatorname{los}$ disturbios $u_{i j}$ en [1] están correlacionados. Se corrige este problema utilizando un método propuesto por Lee (1983) que posibilita que el modelo de participación policotómico se transforme en un problema de decisión binaria, como fue señalado más arriba.

Si $\Phi$ denota la función de distribución normal estándar, la transformación $J=\Phi^{-1} F$ es estrictamente creciente y la variable aleatoria transformada $\pi_{s}{ }^{*}$ [ecuación 2], donde $\pi_{s}{ }^{*}$ $=J\left(\pi_{s}\right)$, también será una variable normal estándar. Por lo tanto, la alternativa $s$ será elegida sólo si $J\left(\delta_{s}{ }^{\prime} X\right)>\pi_{s}{ }^{*}$. Esta especificación implica que, condicionado a que se elija la alternativa $s$,

$$
\begin{gathered}
W_{s}=\beta_{s}^{\prime} Z_{s}-\rho_{s}\left(\phi\left(J\left(\delta_{s}^{\prime} X_{s}\right)\right) / F\left(\delta_{s}^{\prime} X_{s}\right)\right)+\xi_{s} \\
=\beta_{s}^{\prime} Z_{s}+\omega_{s},
\end{gathered}
$$

donde $E\left(\xi_{s} \mid s\right.$ elegido $)=0, \phi$ es la densidad de una normal estándar y $X_{s}$ es una partición de $X$ (véase Lee, 1983).

Por lo tanto, la ecuación [5] se estima para $s=1$, utilizando los estimadores de los parámetros $\delta$ calculados del modelo Logit. Reemplazando estos estimadores en [5], en la segunda etapa se estima que

$$
W_{1}=\beta_{1}^{\prime} Z_{1}-\rho_{1}\left(\phi\left(J\left(\hat{\delta}_{1}^{\prime} X_{1}\right)\right) / F\left(\hat{\delta}_{1}^{\prime} X_{1}\right)\right)+\tilde{\xi}_{1} .
$$

Los disturbios de la ecuación [6] son heterocedásticos y están correlacionados a través de las distintas observaciones muestrales. Se construye la matriz de varianzas y covarianzas asintóticamente correcta utilizando una modificación del procedimiento seguido por Lee, Maddala y Trost (1980). ${ }^{2}$

A partir de esta ecuación, es posible entonces asignar un salario a aquellas personas en edad activa que no lo tienen porque se encuentran desempleadas o inactivas, para el caso de que resulten seleccionadas para cambiar de situación de actividad. Para ello, es preciso generar un término de error para cada una de ellas como si estuvieran empleadas. Como el residuo de la ecuación de salarios, $\omega_{1}$, no se observa para estos individuos, se genera condicionado al que se observa. Esto se hace generando $\psi_{1}$ desde una distribución normal estándar y luego calculando,

\footnotetext{
${ }^{2}$ Para una exposición más detallada de la forma de corrección puede verse González Rozada y Menéndez (1999).
}

$$
\text { [7] } \hat{\omega}_{2}=-\hat{\rho}_{1}\left(\phi\left(J\left(\hat{\delta}_{1}^{\prime} X_{2}\right)\right) / F\left(\hat{\delta}_{1}^{\prime} X_{2}\right)\right)+\hat{\sigma}_{\xi_{1}} \Psi_{1}
$$

El primer término de la ecuación [7] es el valor esperado de $\omega_{2}$ condicionado a que la persona esté empleada. La estimación de la desviación estándar de $\xi_{1}\left(\sigma \xi_{1}\right)$ se obtiene de la estimación mínimo cuadrática de [6]. Por lo tanto, los salarios para los desempleados y los inactivos se calculan como

$$
\widehat{W}_{s}=\hat{\beta}_{1}^{\prime} Z_{s} \hat{\omega}_{2}
$$

donde $s=2,3$.

\section{Procedimientos de microsimulación}

Utilizando las probabilidades obtenidas de la estimación del modelo policotómico de participación, así como los coeficientes estimados para las funciones de ingreso laboral para el año $t$ se evalúa el efecto sobre la distribución del ingreso familiar per cápita de los cambios que se registraron, entre ese año y $t+k$, en la participación económica, el desempleo, la escolaridad de la fuerza de trabajo y la rentabilidad del capital humano. Para ello se simularon varias poblaciones contrafácticas, replicando secuencial y acumulativamente en la población de $t$ los valores que esas variables registraron en $t+k$. Comparando los indicadores de desigualdad de la distribución del ingreso efectiva con los correspondientes a las distribuciones computadas con las poblaciones contrafácticas, se cuantifica el efecto de los cambios en aquellas variables.

\section{i) Efecto del cambio en la tasa de participación}

La estimación del modelo policotómico de participación en el año $t$, permite obtener, como se indicó, las probabilidades marginales de que cada individuo esté empleado $\left(\mathrm{P}_{t, 1}\right)$, desempleado $\left(\mathrm{P}_{t, 2}\right)$ o fuera de la fuerza de trabajo $\left(\mathrm{P}_{t, 3}\right)$.

El siguiente paso consistió en ordenar a los individuos de la población del año $t$ de acuerdo con $\mathrm{P}_{\mathrm{t} \text {,in }}$, la probabilidad de estar activo (que es la suma de $\mathrm{P}_{t, 1}$ y $\mathrm{P}_{t, 2}$ ) y $\mathrm{P}_{\mathrm{t}, 1}$ de forma tal de ubicar en los primeros lugares de la muestra a aquellas personas con mayor probabilidad de pertenecer a la fuerza de trabajo. Si $f \%$ es la proporción de personas que participan de la fuerza de trabajo en el año $t+k$, ese ordenamiento permite identificar el conjunto de $f \%$ individuos de la población del año $t$ que participarían de la fuerza de trabajo. De esta forma se cambia la tasa de participación del año $t$ por la del año $t+k$. El $f \%$ de la población del año $t$ que integraría la fuerza de trabajo está ordenada $\left(\right.$ por $\mathrm{P}_{\mathrm{t}, 1}$ ) de forma tal que primero aparecen aquellas personas que tienen mayor probabilidad de estar empleadas, de acuerdo con sus características en $t$. Por lo tanto, identificando en este ordenamiento la proporción $(e \%)$ de personas empleadas en el año $t$ se clasifica la población activa entre empleados y desempleados.

Esta forma contrafáctica de organización de la población del año $t$ asegura que el $f \%$ de la población que tiene mayor probabilidad de pertenecer a la fuerza de trabajo, dadas sus características en ese año, hubiera pertenecido efectivamente a ella y que el $e \%$ de la población activa del año $t$ que tiene mayor probabilidad de estar empleada, lo hubiera estado. 
Una vez organizada la población contrafáctica es preciso asignar los ingresos laborales. Para aquellas personas que no cambian de condición de actividad nada se modifica: quienes estaban desempleados o inactivos registran un salario igual a cero y quienes estaban empleados mantienen su ingreso declarado. A los que pasan de estar desempleados o inactivos en $t$, a estar empleados en la población contrafáctica, se les asigna la remuneración obtenida aplicando [8].

Con estas remuneraciones de las personas se recalculan los ingresos familiares y los indicadores de su distribución. La comparación de las diversas medidas de desigualdad de la distribución original del año $t$ y de la distribución computada a partir de la población contrafáctica permite cuantificar el efecto del cambio registrado por la tasa de participación entre $t$ y $t+k$ sobre la distribución del ingreso familiar.

\section{ii) Efecto del cambio en la tasa de desempleo}

Para captar el efecto adicional del cambio en la tasa de desempleo (dado el del cambio en la tasa de participación) entre $t$ y $t+k$, se utiliza el mismo procedimiento descrito en el apartado i); esto es, primero se reordena la población contrafáctica utilizando $\mathrm{P}_{t, \text { in }}$ y luego utilizando $\mathrm{P}_{t, 2}$, de forma tal que primero aparezcan aquellos individuos con menor probabilidad de estar desempleados, dadas sus características en el año $t$. Si $d \%$ es la proporción de personas desempleadas en $t+k$, se obtiene la nueva población simulada que identifica el conjunto de individuos que estarían desocupados en $t$ si prevaleciese la tasa de desocupación de $t+k$. Una vez simulada la población contrafáctica se asignan las remuneraciones, ya sea manteniendo la registrada o — para los que cambian de condición- la obtenida de [8]. La comparación de la consiguiente distribución del ingreso familiar (que se ha simulado con las tasas de actividad y desempleo de $t+k$ ) con la contrafáctica calculada en el apartado anterior i) (que se ha simulado con la tasa de participación de $t+k$ y la de desempleo de $t$ ) permite evaluar el efecto de la variación del desempleo.

\section{iii) Efecto del cambio en la estructura educacional de la} población ocupada

Primero se calculó la proporción de personas con educación primaria completa e incompleta $(\mathrm{p} \%)$, secundaria completa e incompleta (s\%) y universitaria completa e incompleta $(\mathrm{u} \%)$ en la población del año $t+k$. Luego se ordenó la población contrafáctica calculada en el apartado ii), dentro de cada condición de actividad (ocupados, desocupados e inactivos), de forma tal que primero aparezcan aquellos con educación primaria, luego los que tienen educación secundaria y por último los que tienen educación universitaria. Dentro del primero de estos estratos (ocupados), se ordenaron las personas dentro de cada categoría educacional de manera aleatoria, utilizando el número al azar que se generara para cada persona con miras a la asignación de los salarios contrafácticos. Luego, seleccionando en este ordenamiento las proporciones de personas con educación primaria $(\mathrm{p} \%)$, secundaria ( $\mathrm{s} \%)$ y universitaria $(\mathrm{u} \%)$ en $t+k$ se construyó la población contrafáctica que refleja la estructura educativa de la población ocupada de $t+k$.

El siguiente paso consistió en asignar las remuneraciones a las personas de esta población que cambian de categoría educacional. A estos perceptores se les asigna una remuneración — declarada o calculada mediante la ecuación [8]equivalente a multiplicar la que tenían por la relación, en el año $t$, entre las remuneraciones medias de su nueva y su antigua categoría educacional. Una vez completados así los ingresos de la población contrafáctica, es posible calcular el ingreso familiar y su distribución. La comparación de esta última con la distribución simulada en el apartado ii) permite apreciar el efecto de los cambios en la estructura educacional sobre la distribución del ingreso familiar.

\section{iv) Efecto de los cambios en las remuneraciones}

Se modificaron las remuneraciones de la población contrafáctica obtenida en el apartado iii) de manera que reflejaran la estructura de remuneraciones del año $t+k$. A cada persona se le asignó una remuneración generada de acuerdo con [6] y [8], pero con los coeficientes estimados de ambas ecuaciones para el año $t+k$. De esta manera toda la población tiene una remuneración de acuerdo a lo que habría obtenido en $t+k$ dadas sus características sociodemográficas. Para aquellos que han cambiado de categoría educacional se multiplica esta nueva remuneración por la relación, en el año $t+k$, entre las remuneraciones medias de su nueva y su anterior categoría educacional. Modificadas de esa manera las remuneraciones de las personas, fue posible calcular la distribución de los ingresos familiares de esta población contrafáctica. La comparación con la distribución derivada de la población contrafáctica obtenida en iii) permite evaluar el efecto ejercido adicionalmente sobre la distribución del ingreso por los cambios en la estructura de remuneraciones.

\section{Bibliografía}

Altimir, O. (1986): Estimaciones de la distribución del ingreso en la Argentina, 1953-1980, Desarrollo económico, vol. 25, $\mathrm{N}^{\circ} 100$, número extraordinario, Buenos Aires, Instituto de Desarrollo Económico y Social (IDES).

Altimir, O. y L. Beccaria (1998): Efectos de los cambios macroeconómicos y de las reformas sobre la pobreza urbana en Argentina, en E. Ganuza, L. Taylor y S. Morley, Política macroeconómica y pobreza en América Latina y el Caribe, Santiago de Chile, Programa de las Naciones Unidas para el Desarrollo/Banco Interamericano de Desarrollo/
Comisión Económica para América Latina y el Caribe (PNUD/ BID/CEPAL).

(2000a): Distribución del ingreso en la Argentina, en D. Heymann y B. Kosacoff (eds.), La Argentina de los noventa: desempeño económico en un contexto de reformas, Tomo I, Buenos Aires, Editorial Universitaria de Buenos Aires (EUDEBA) Oficina de la CEPAL en Buenos Aires.

(2000b): El mercado del trabajo bajo el nuevo régimen económico en Argentina, en D. Heymann y B. Kosacoff (eds.), La Argentina de los noventa: desempeño económico en un 
contexto de reformas, Tomo I, Buenos Aires, EUDEBA/Oficina de la CEPAL en Buenos Aires.

(2001): El persistente deterioro de la distribución del ingreso en la Argentina, Desarrollo económico, vol. 40, № 160, Buenos Aires, IDES.

Bourguignon, F., M. Fournier y M. Gourgand (1998): Distribution, development and education: Taiwan, 1979-1994, trabajo presentado al Primer Taller de la Red sobre Desigualdad y Pobreza, Buenos Aires, Asociación de Economía de América Latina y el Caribe /Banco Interamericano de Desarrollo/Banco Mundial (ADEALC)/BID/Banco Mundial).

Bourguignon, F., F. Ferreira y N. Lustig (2001): The microeconomics of income distribution dynamics: A comparative analysis of selected developing countries, trabajo presentado al Encuentro de la Sociedad Econométrica (Buenos Aires), inédito.

Canitrot, A. (1981): Teoría y práctica del liberalismo. Política antiinflacionaria y apertura económica en la Argentina, 19761981, Desarrollo económico, vol. 21, № 82, Buenos Aires, IDES.

(1993): Inestabilidad y flujos de comercio en Argentina, 1978-1981, serie Reformas de política pública, № 2, LC/L.732, Santiago de Chile, CEPAL.

Damill, M., R. Frenkel y R. Maurizio (2002): Argentina; una década de convertibilidad. Un análisis del crecimiento, el empleo y la distribución del ingreso, Santiago de Chile, Oficina Internacional del Trabajo.

Frenkel, R. y M. González Rozada (1998): Apertura, productividad y empleo: Argentina en los años 90, serie de Documentos de economía, $N^{\circ}$ 9, Buenos Aires, Universidad de Palermo/Centro de Estudios de Estado y Sociedad (CEDES).

(2000): Tendencias de la distribución de ingresos en los años noventa, serie de Documentos de economía, $\mathrm{N}^{\circ} 16$, Buenos Aires, Universidad de Palermo/CEDES.

Gerchunoff, P. y L. Llach (1998): El ciclo de la ilusión y el desencanto. Un siglo de políticas económicas argentinas, Buenos Aires, Ariel.
González Rozada, M. y A. Menéndez (1999): The effect of unemployment on labor earnings inequality in Argentina, Princeton, New Jersey, Princeton University, inédito.

Heymann, D. (2000): Políticas de reforma y comportamiento macroeconómico, en D. Heymann y B. Kosacoff (eds.), $L a$ Argentina de los noventa: desempeño económico en un contexto de reformas, Tomo I, Buenos Aires, EUDEBA/Oficina de la CEPAL en Buenos Aires.

INDEC (Instituto Nacional de Estadística y Censos (varios años): Encuesta Permanente de Hogares, Buenos Aires.

Katz, J. y B. Kosacoff (1989): El proceso de industrialización en la Argentina: evolución, retroceso y prospectiva, LC/BUE/G.104, Buenos Aires, Oficina de la CEPAL en Buenos Aires.

Llach, J. y C. Sánchez (1984): Los determinantes del salario en la Argentina, Estudios, $\mathrm{N}^{\circ} 29$, Córdoba, Argentina, Instituto de Estudios Económicos sobre la Realidad Argentina y Latinoamericana (IIERAL).

Lee, L-F (1983): Generalized Econometric Models with selectivity, Econometrica, Vol. 51, № 2, pp. 507-512, Evanston, Illinois, The Econometric Society.

Lee, L, G. S. Maddala y R.P. Trost (1980): Asymptotic covariance matrices of two-stage Tobit methods for simultaneous equation models with selectivity, Econometrica, $\mathrm{N}^{\circ} 48$, Evanston, Illinois, The Econometric Society.

McFadden, D. (1974): Conditional logit analysis of qualitative choice behavior, en P. Zarembka (ed.), Frontiers in Econometrics, Nueva York, Academic Press.

Ramos, A. y R. Martínez (2000): El proceso de inversiones en la economía argentina. Impacto de las reformas de política y procesos de decisión ante un cambio de incertidumbres, en D. Heymann y B. Kosacoff (eds.), La Argentina de los noventa: desempeño económico en un contexto de reformas, Tomo I, Buenos Aires, EUDEBA/Oficina de la CEPAL en Buenos Aires. 